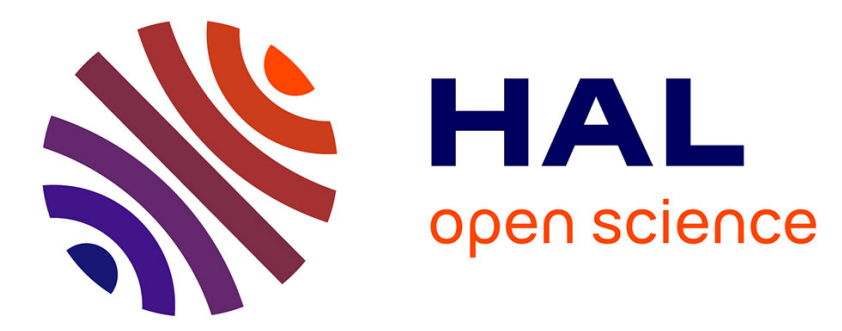

\title{
Les origines du Vedānta comme tradition scolastique. État du problème, nouvelles hypothèses
} Hugo David

\section{To cite this version:}

Hugo David. Les origines du Vedānta comme tradition scolastique. État du problème, nouvelles hypothèses. Bulletin de l'Ecole française d'Extrême-Orient, 2016, 102 (1), pp.9-44. 10.3406/befeo.2016.6230 . halshs-02417310

\section{HAL Id: halshs-02417310 \\ https://shs.hal.science/halshs-02417310}

Submitted on 18 Dec 2019

HAL is a multi-disciplinary open access archive for the deposit and dissemination of scientific research documents, whether they are published or not. The documents may come from teaching and research institutions in France or abroad, or from public or private research centers.
L'archive ouverte pluridisciplinaire HAL, est destinée au dépôt et à la diffusion de documents scientifiques de niveau recherche, publiés ou non, émanant des établissements d'enseignement et de recherche français ou étrangers, des laboratoires publics ou privés. 


\title{
Les origines du Vedānta comme tradition scolastique État du problème, nouvelles hypothèses
}

\author{
Hugo DAVID
}

\begin{abstract}
Résumé
La présente étude examine l'histoire ancienne du Vedānta sous l'angle des conceptions herméneutiques propres à cette école, plus que de l'histoire des doctrines comme cela a généralement été le cas par le passé. Partant de l'opposition entre l'hypothèse d'une crise interne à la tradition exégétique et celle, contradictoire, d'un courant philosophique indépendant ayant emprunté sur le tard la forme de l'exégèse védique, on s'intéresse à l'évolution des représentations du Texte Sacré en milieu vedāntique, reflétées dans ses premiers manifestes et dans plusieurs autres sources anciennes (doxographies, etc.); l'œuvre de Bhartrhari reçoit alors une attention particulière. L'article s'efforce de replacer dans son contexte l'apparition tardive de la catégorie des "énoncés du Vedānta» (vedāntavākya) et d'y voir le signe d'un changement radical dans la conception des Écritures propre aux écoles brahmaniques entre le $V^{e}$ et le vIII siècle.
\end{abstract}

Mots-clés: Vedānta; Mīmāṃsā; herméneutique; exégèse du Veda; philosophie indienne; Bharțarhari; Maṇḍana Miśra; vedāntavākya; pravāda; arthavāda.

\begin{abstract}
This study addresses the question of the origins of Vedanta as the UttaraMìmānsā ("Later Exegesis"), focussing on its conceptions in the field of hermeneutics rather than on the evolution of its doctrines. While some scholars consider that the Uttara-Mìmāmsā was born from an internal crisis in the exegetical tradition, others claim that Vedanta was originally an independent philosophical movement that only later adopted the form of Vedic exegesis. Building on this opposition, the article considers various ruptures in the early history of the Vedantic notion of the Sacred Text, reflected in works of the school and in other ancient sources, with a special focus on Bhartrhari. It thus attempts to place in context the late appearance of the category of "utterances of the Vedānta," positing that it is a sign of a radical change in the conception of the Scriptures of the Brahmanical tradition between the 5th and 8th centuries.
\end{abstract}

Keywords: Vedānta; Mīmāṃsā; hermeneutics; Indian philosophy; Vedic exegesis; Bhartrohari; Mạ̣ụana Miśra; vedāntavākya; pravāda; arthavāda. 



\title{
Les origines du Vedānta comme tradition scolastique État du problème, nouvelles hypothèses
}

\author{
Hugo DAVID*
}

\section{Introduction : le Vedānta, une branche dissidente de la Mīmāmsāen?}

Si les histoires de la pensée indienne évoquent encore fréquemment le Vedānta comme l'un des six «systèmes philosophiques» (darśana) du brahmanisme orthodoxe, on sait désormais que cette classification est relativement récente, et qu'elle est loin d'avoir le caractère structural qu'on lui a longtemps attribué 1 . Tout au long de leur histoire, la manière la plus commune pour les adeptes du Vedānta de penser leur propre activité intellectuelle était de la décrire comme une exégèse (mìmāms $\bar{a})$ de certains énoncés du Veda, les «énoncés du Vedānta» (vedāntavākya), couramment identifiés avec les énoncés des Upanișad. Ainsi Śankkara (deuxième moitié du vIII ${ }^{\mathrm{e}}$ siècle?), dans le premier chapitre de son Commentaire sur les Aphorismes du Brahman (Brahmasūtrabhāṣya, désormais BSūBh), désigne-t-il les Brahmasūtra comme la

\footnotetext{
* École française d'Extrême-Orient, hugo.david@efeo.net. Une version plus brève, en anglais, de cette étude, a été présentée à Paris en novembre 2014 à l'occasion de la première de deux journées d'études «Pratique des scolastiques et scolastiques des pratiques» organisées par Émilie Aussant et Gérard Colas; elle paraîtra prochainement dans le volume issu de ces journées, intitulé «Les scolastiques indiennes: naissances, développements, interactions» (titre provisoire), dirigé par É. Aussant et G. Colas. Je remercie les éditeurs de ce volume et les participants à ces journées pour leurs remarques et critiques. La présente recherche a également bénéficié du soutien de l'Académie des Sciences d'Autriche (projet FWF n ${ }^{\circ}$ P25287 - G15, «Le langage et l'action dans la philosophie brahmanique classique. Une étude du Vidhiviveka de Mandana Miśra»). Les recherches préliminaires à cette étude ont été engagées lors de mon séjour à l'université de Cambridge (Faculté d'études asiatiques et moyen-orientales), effectué en 2013-2014 avec le soutien de la Société royale de Grande-Bretagne (Newton International Fellowship). Je remercie également Elliot M. Stern pour m'avoir généreusement communiqué, depuis 2012, d'importants travaux inédits relatifs au Vidhiviveka et à ses commentaires.

1. Voir sur ce point les travaux de Jhā (1964: 1-2), Halbfass (1988: 351-353) et Gerschheimer (2007). Comme le montre bien ce dernier, l'idée du Vedānta comme l'un des six darśana résulte sans doute de l'adaptation à époque tardive d'une liste de six «doctrines de spéculation» (tarka) courante en Inde et dans le monde indianisé dans la seconde moitié du premier millénaire, comprenant à la fois des systèmes brahmaniques ou para-brahmaniques (Nyāya, Vaiśeșika, Sāṃkhya) et des systèmes non brahmaniques (bouddhisme, jaïnisme, matérialisme). Un tel remaniement, dont découle au même titre la notion de six «systèmes philosophiques orthodoxes» (āstikadarśana) ou «points de vue» sur la Révélation védique, pourrait s'être produit autour des XIII ${ }^{e}$ et XIV ${ }^{e}$ siècles, date à laquelle les tenants du Vedānta non dualiste (Advaita Vedānta) commencent à composer leurs propres doxographies. Rien n'indique, d'ailleurs, qu'il ait été généralement accepté. Voir sur ce point les nombreuses exceptions mentionnées par Jhā (1964: 2) et Halbfass (1988: 351-352). À l'exception notable du doxographe jaïn Haribhadra (VII siècle), qui inclut la Mīmāṃsā dans la liste des six systèmes (darśana) décrits dans son Saddarśanasamuccaya (voir Gerschheimer 2007:240-241), les listes de tarka/darśana antérieures à l'an 1000 ne comprennent généralement ni le Yoga, ni aucun des deux systèmes issus de l'exégèse du Veda.
} 
«science de l'exégèse des [énoncés du] Vedānta» (vedāntamīmāmsāsáāstra - BSūBh 1.1.1, p. 46.1) et sa propre entreprise comme une «exégèse des énoncés du Vedānta» (vedāntavākyamīmāmssāa-ibid., p. 83.2)². Les auteurs plus tardifs qualifient cette forme particulière d'exégèse à visée contemplative d'«Exégèse postérieure» (Uttara-Mīmāṃsā), l'opposant ainsi à une «Exégèse antérieure » (Pūrva-Mīmāṃsā) centrée sur l'interprétation du rituel védique 3 . La question des rapports qu'entretient à date ancienne le Vedānta ${ }^{4}$ avec «la» Mīmāṃsā par excellence, celle des Aphorismes sur l'Exégèse (Mīmāmssāsūtra) attribués à Jaimini (premiers siècles de n.è.?), est donc de première importance pour comprendre les plus anciens développements de ce système de pensée et sa place dans le paysage intellectuel de l'Inde médiévale.

De fait, on constate depuis une trentaine d'années un intérêt grandissant des spécialistes pour les relations entre les «deux Mīmāṃsā». Dans un article célèbre publié entre 1981 et 1994, Asko Parpola reprend ainsi l'idée, formulée pour la première fois par Jacobi, selon laquelle les deux systèmes n'en auraient formé à l'origine qu'un seul ${ }^{5}$, et y superpose sa propre hypothèse d'une unique collection d'Aphorismes sur l'Exégèse (Mīmāms āsūutra) en vingt livres et deux sections : antérieure $\left(p \bar{u} r v a^{\circ}\right)$ et postérieure $\left(u t t a r a^{\circ}\right)$. Cette unique collection aurait par la suite été divisée de manière à former trois collections d'aphorismes indépendantes: les douze livres des Mìmāmsāāütra commentés par Śabarasvāmin, les quatre livres du Saṃkarṣa- ou Devatākāṇ̣̂, et enfin les

2. Les expressions vedāntavākyamīmāmsāa vedāntamīmāmsā et vedāntamīmāmsāásāstra se trouvent, immédiatement après Śankkara, dans la Pañcapādikā de Padmapāda (fin du VIII ${ }^{e}$ siècle), qui leur oppose la vidhivrttamīmāmsāa («l'exégèse des injonctions et des récits [= les arthavāda?]»). Voir Nakamura 1983: 410-411 et Bronkhorst 2007: 63. L'expression śārīrakamīmāmsā qu'emploie Śankara (BSūBh 1.1.1, p. 46.4) attend toujours une explication convaincante. Vācaspati Miśra (Bhāmatī 1.1.1, p. 45.23-24) l'explique en référence à «ce qui possède un corps (śarīra)», à savoir l'âme individuelle (jīvātman), mais rien n'indique que cette interprétation soit partagée par tous les auteurs.

3. Pour un aperçu des interprétations de ces deux expressions proposées dans la littérature secondaire, voir Nakamura 1983 : 411-412 et Parpola 1981: 145-146, qui récuse cependant le caractère original des deux désignations (voir infra note 6). Il est difficile de retracer l'origine exacte de la distinction entre Pūrva- et Uttara-Mīmāmmsā, mais il se pourrait qu'elle ne soit pas très ancienne. Bronkhorst (2007: 64) en mentionne deux occurrences chez Yāmuna et Rāmānuja, et il semble effectivement difficile de la faire remonter beaucoup plus loin. L'expression uttaramīmāmsā ne se trouve ainsi ni chez Manḍana Miśra ni, à ma connaissance, chez Śańkara, même si ce dernier parle à

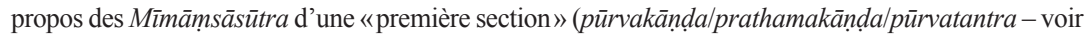
Nakamura 1983 : 411). Le fait que ces deux expressions se rencontrent pour la première fois sous la plume d'auteurs śrīvaiṣnava, ces derniers plaidant pour l'unité des deux systèmes (aikaśāstrya), pourrait d'ailleurs n'être pas une pure coïncidence, comme le suggère justement Bronkhorst (2007: 66).

4. C'est par convention que je parlerai ici «du» Vedānta pour désigner un courant de pensée philosophique et exégétique; l'appellation «Vedānta» comme nom d'école (au singulier) ne se rencontre cependant pas, à ma connaissance, dans les textes sanskrits du premier millénaire. Voir aussi sur ce point les remarques de Nakamura (1983: 98 et 302), qui ne propose malheureusement aucune hypothèse sur la date d'apparition de l'usage du terme au singulier. Comme il le note justement (p. 90-95), les deux seuls usages du terme vedānta attestés dans les textes antérieurs à l'an 1000 sont, d'une part, pour désigner une certaine catégorie d'énoncés védiques constituant la «fin du Veda» (vedāntāh, «les» Vedāntas) et, d'autre part, pour exprimer l'idée d'un «accomplissement du Veda», de son «sens ultime», voire d'un accomplissement de la connaissance dont le Veda constitue l'épitomé (voir sur ce point le passage de la Tarkajvālā attribuée à Bhavya cité ci-dessous note 16).

5. Voir Jacobi 1911 : 18 (= Jacobi 1970: 576): «(...) at Śabarasvāmin’s time the Pūrva- and UttaraMīmāṃsās still formed one philosophical system, while after Kumārila and Śankkara they were practically two mutually exclusive philosophies ». L'idée du système unique est également adoptée par Frauwallner (1968: 110). 
quatre livres des Brahmasūtra attribués à Bādarāyaṇa, dont la forme actuelle serait le fruit d'une réécriture des quatre derniers livres de la collection originale ${ }^{6}$. L'hypothèse de Parpola, qui prolonge un certain nombre d'observations faites dans les années 1950 par Nakamura ${ }^{7}$, a récemment fait l'objet d'une critique détaillée par Johannes Bronkhorst (2007), qui avance sur le même problème un point de vue radicalement opposé. Selon Bronkhorst, qui récuse tant l'hypothèse de la collection unique que l'idée d'une école exégétique commune ${ }^{8}$, ce n'est que tardivement qu'un courant vedāntique d'abord indépendant aurait adopté les méthodes et les présupposés de la Mīmāṃsā de manière à former une école rivale d'exégèse védique. De la sorte, on devrait distinguer parmi les Vedāntin ceux qui «ne sont pas des Mīmāṃsaka» - sont alors mentionnés pêle-mêle Gauḍapāda, Ādiśeșa, Bhartronari et l'auteur du Mokṣopāyade ceux qui «sont des Mīmāmssaka», dont les chefs de file seraient, d'une part, Maṇdana Miśra, de l'autre, les premiers commentateurs sur les Brahmasūtra: Śan̉kara, Bhāskara et Rāmānuja9 . Les raisons de cette agrégation sur le tard à la Mīmāṃsā sont moins claires, et semblent se réduire pour Bronkhorst au fait que les Vedāntin de cette seconde catégorie, en suivant scrupuleusement les règles d'interprétations élaborées par la Mīmāmssā, auraient cherché avant tout à «ancrer les idées vedāntiques dans le Veda éternel» (p. 77). Cette nouvelle «respectabilité» devait cependant se payer au prix fort, faisant passer le Vedānta du statut d' 'école philosophique» (p. 28) enseignant le chemin vers la libération sur la base des facultés humaines de raisonnement et d'observation à celui d'école d'«interprétation védique» (p. 34) dérivant l'intégralité de ses positions du Veda, désormais considéré comme la source éternelle et infaillible de tout énoncé valide sur le Brahman, la libération et les moyens d'y accéder.

6. Rappelons que, selon Parpola (1981: 147-148), les qualificatifs $p \bar{u} r v a^{\circ}$ et $u t t a r a^{\circ}$ ne s'appliquent pas à l'origine à deux systèmes philosophiques ou exégétiques (les deux Mīmāṃsā), mais aux deux parties d'un même texte: la collection originale en vingt livres des Mìmāmsāāsūtra. L'opposition ne serait donc pas, selon lui, entre une Pūrvamīmāṃsā de tendance ritualiste et une Uttaramīmāṃsāà visée plus spéculative, mais simplement entre les deux parties d'une même collection d'aphorismes (Pūrva-/Uttara-Mīmāṃsāsūtra), division dont on trouve plusieurs équivalents dans la littérature védique ou immédiatement post-védique (p. 148-149). Même en admettant l'hypothèse de la «collection unique», cette interprétation me semble poser deux difficultés principales. Tout d'abord, une division de la collection en deux sections laisse dans l'ombre le statut du Saṃkarșakāṇda, que Parpola considère apparemment (quoiqu'il ne s'en explique guère) comme partie intégrante du/des «Pūrva-Mīmāṃsāsūtra» (p. 152). Par ailleurs, s'il est évidemment possible que les auteurs médiévaux se soient mépris sur le sens des adjectifs $p \bar{u} r v a^{\circ}$ et $u t t a r a^{\circ}$ (une distinction qui appartient, selon Parpola, à l'univers védique), le fait que l'opposition entre Pūrva ${ }^{\circ}$ et Uttaramīmāṃsā n'apparaisse qu'assez tardivement (voir supra note 3) constitue assurément un point faible de cette interprétation. Sur ce point, voir aussi Bronkhorst 2007 : 64-65.

7. Voir Nakamura 1983 : 409-414. Comme il s'en explique dans une note (Parpola 1994: 293, n. 1), Parpola n'a pu consulter l'ouvrage de Nakamura (publié une première fois en Japonais entre 1950 et 1956) qu'après la parution de sa traduction anglaise en 1983, soit après la publication de la première partie de son article en 1981. Les deux savants semblent donc être arrivés indépendamment à des conclusions proches.

8. Une critique similaire avait déjà été adressée à l'hypothèse de Jacobi par Keith (1920).

9. Un point qui n'est jamais pleinement éclairci par Bronkhorst est l'inscription de ces deux tendances («mīmāṃsaka» et «non mīmāṃsaka») dans la chronologie du Vedānta. Ces deux courants ont-ils jamais coexisté, ou assiste-t-on au contraire au remplacement irréversible du premier par le second? Et dans ce dernier cas, comment comprendre la place dans l'histoire du Vedānta des Brahmasūtra, que Bronkhorst rattache clairement à la branche «mīmāṃsaka» des Vedāntin (p. 70-71), mais dont il ne discute à aucun moment la date? 
Mon intention n'est pas ici d'entrer dans le détail de cette polémique, qui n'est d'ailleurs pas close ${ }^{10}$. Assurément l'un des grands mérites de l'hypothèse de Bronkhorst est d'attirer l'attention sur certaines ruptures dans l'histoire du Vedānta là où celle de Parpola avait au contraire tendance à les aplanir pour mieux souligner la continuité des «deux Mīmāṃsā» avec la pensée védique $^{11}$. Il est par exemple exact d'affirmer, comme le fait Parpola, que l'usage du thème désidératif mìmāms- («mener une enquête») est ancien, et précède en tout cas largement la date de rédaction des Mìmāmsāsūtra ${ }^{12}$. La forme nominale mìmāmsāa («enquête, exégèse») apparaît elle-même à au moins trois reprises dans le corpus upanișadique ancien (BĀU 1.5.21, ChU 5.11.1 et TaiU 2.8.1). On remarque toutefois qu'elle n'y désigne jamais l'exégèse d'un texte, mais toujours l'enquête sur la nature d'une chose (que celle-ci appartienne ou non à l'univers du rituel védique): les observances (vrata-BĀU), l'Ätman/Brahman (ChU), la félicité (ānanda-TaiU). Cette utilisation du terme mìmāmsā est donc tout à fait distincte de celle qu'en fait par exemple Śañkara, qui l'emploie quant à lui toujours pour parler d'une enquête sur les textes vedāntiques, notamment pour désigner la résolution d'un doute les concernant ${ }^{13}$. Cet usage, inconnu du Vedānta plus ancien ${ }^{14}$, marque donc, semble-t-il, un changement important dans la manière dont les Vedāntin appréhendent leur propre discipline, changement qu'on voit se produire au tournant des $\mathrm{VII}^{\mathrm{e}}$ et $\mathrm{VIII}^{\mathrm{e}}$ siècles et dont il est essentiel de rendre compte. Dans cette étude, je souhaite apporter un éclairage nouveau sur ce virage incontestable dans l'histoire de l'exégèse brahmanique en retraçant, des origines à la fin du vIII' siècle, l'évolution des idées vedāntin sur le plan de l'herméneutique plutôt que de la doctrine métaphysique ou sotériologique: que représente, pour les Vedāntin aux différentes époques, le texte (ou l'ensemble de textes) qu'ils nomment «le/les Vedānta(s)» (vedāntaḥ/vedāntāh)? Quels textes ces termes recouvrent-ils exactement? Comment, enfin, cet ensemble s'articule-t-il avec le Veda, et quel type d'autorité y est-elle attachée?

Mon hypothèse principale est que se produit, entre le début du VII siècle et la fin du VIII ${ }^{\mathrm{e}}$ siècle, un changement de perspective sur le texte sacré de la part des Vedāntin, marqué par l'apparition d'une nouvelle catégorie

10. Dans une étude parue récemment (Bronkhorst 2014), Bronkhorst répond ainsi à certaines critiques faites à son article de 2007 par Aklujkar (2011), qui prend à son tour parti pour ce qu'il nomme «l'unité des deux Mīmāṃsās». L'article en question ne permet cependant pas de déterminer avec certitude la position d'Aklujkar vis-à-vis des thèses de Parpola.

11. Voir en particulier Parpola 1981: 158-162.

12. Voir les exemples tirés des Brāhmaṇa mentionnés par Parpola (1981: 160-161) et Verpoorten (1987: 3).

13. Mis à part les deux occurrences dans le commentaire de Śaṅkara au Brahmasūtra 1.1.1 citées plus haut, le verbe mīmāms- apparaît à trois reprises dans le troisième livre du Bhāșya (mīmāmsyate - BSūBh 3.2.11; mīmāmsāmahahe - 3.3.25; mīmāmsamāna - 3.4.1), à chaque fois dans la portion introductive d'un chapitre (adhikaraṇa) et pour faire référence à l'examen d'un doute particulier relatif à l'interprétation de tel ou tel passage upanișadique.

14. Le terme mīmāms ā et son équivalent verbal mìmāmssate sont totalement absents de l'Ágamaśāstra de Gauḍapāda, du Paramārthasāra d'Ādiśeșa, ainsi que des sections des doxographies de Bhavya et Siddhasena Divākara consacrées au Vedānta (voir infra, section 1). Concernant la littérature upanișadique proprement dite, les seules occurrences répertoriées par Jacob (1988: 745) sont les trois dont il vient d'être question, qui appartiennent toutes à ses strates les plus anciennes. 
herméneutique inconnue des exégètes du Veda encore un ou deux siècles plus tôt, celle des vedāntavākya (les «énoncés du Vedānta») ou upaniṣadvākya ( "énoncés upaniṣadiques»). Tels qu'ils sont conçus typiquement par Śan̉kara (BSūBh 1.1.4), les énoncés du Vedānta sont une catégorie d'énoncés védiques (vedavākya) faisant référence à un objet existant ou réalisé (bhūta\% siddhārtha), le Soi Suprême (paramātman) ou Brahman. De tels énoncés, distincts des injonctions (vidhi) rituelles, jouissent néanmoins d'un statut égal et se distinguent en cela des passages mythologiques, analyses sémantiques, etc. regroupés dans la catégorie des «discours sur les choses» (arthavāda), lesquels sont quant à eux strictement subordonnés aux injonctions. La création de cette catégorie herméneutique inédite, qui coïncide chronologiquement avec le projet d'un commentaire global sur les Upanișad dont l'œuvre de Śankara constitue le premier exemple achevé, marque également l'intégration d'un corpus vedāntique aux contours encore flous à l'ensemble textuel le plus sacré du brahmanisme, le Veda, et initie du même geste les diverses tentatives pour en établir le canon. Plus que d'un rattachement superficiel à la Mīmāṃsā ou d'une tentative pour la supplanter, il s'agit là d'une véritable révolution théorique opérée de l'intérieur par l'exégèse, dont on peut suivre les principales étapes dans l'œuvre de Bhartrohari, Kumārila, Maṇḍana Miśra et Śaṅkara. Partant des conceptions rudimentaires de l'Écriture dont témoignent tant la littérature vedāntique la plus ancienne que les premières doxographies (bouddhistes et jaïnes), je chercherai dans un second temps à mettre en évidence le paradoxe que représente, d'un point de vue herméneutique, la construction d'une pensée philosophique sur la base d'un texte considéré comme exclusivement normatif, paradoxe exposé de manière exemplaire au v siècle par Bhartrhari. Je m'efforcerai enfin de saisir, à travers l'œuvre exégétique de Maṇạana Miśra, la naissance du Vedānta comme tradition scolastique adoptant la forme de l'exégèse védique tout en en minant les présupposés les plus élémentaires, et évoluant désormais en référence à un corpus clos.

\section{Part de l'Écriture dans le Vedānta ancien}

On doit tout d'abord remarquer que, contrairement à d'autres écoles philosophiques qui lui sont contemporaines, le Vedānta n'est jamais défini dans les sources anciennes en référence à un fondateur réel ou mythique (Bādarāyaṇa, Vyāsa ou autre), mais presque toujours par rapport au corpus scripturaire dont il se réclame, les Upanișad, ou (beaucoup plus rarement) à un point de doctrine $^{15}$. Ainsi, au vi ${ }^{\mathrm{e}}$ siècle, Bhavya/Bhā(va)viveka évoque-t-il - pour la première fois, semble-t-il - dans ses Madhyamakahrdayakārikā (MHK) les «partisans du/des Vedānta(s)» (vedāntavādin - MHK 8.1) ${ }^{16}$. Vers la même

15. L'appellation brahmavādin («partisan du Brahman»), par exemple, est utilisée assez fréquemment par Śankara dans le second adhyāya du Brahmasūtrabhāsya $(2.1 .6,2.1 .29,2.2 .9,2.2 .38$, 2.3.53). Elle n'y désigne cependant jamais une «école» à proprement parler, mais plutôt le tenant d'une certaine position philosophique dans un contexte polémique.

16. Remarquons toutefois que la Tarkajvālāa - généralement considérée comme le commentaire de Bhavya sur ses propres stances (voir cependant la discussion récente dans Krasser 2012: 569577) - glose le terme vedānta sans référence apparente à un corpus textuel: rig pa 'i mthar phyin 
époque, mention est faite de certains «partisans du Veda» (vedavādin) dans l'œuvre du doxographe jaïn Siddhasena Divākara (vi siècle?), qui décrit dans sa Vedavādadvātrimiśikā («Trente-deux [stances] sur le Vedavāda») une forme de monisme inspiré des Upanișad qu'on a pu (avec raison) rapprocher du Vedānta ${ }^{17}$. La Yuktidīpikā (YD), qui pourrait avoir été composée autour de l'an $700^{18}$, mentionne à son tour les aupaniṣadāh («ceux qui se réclament des Upanișad»), et désigne par ce nom les tenants de l'unicité du soi (ātman) par opposition à ceux qui admettent une pluralité de sujets pensants ${ }^{19}$. Un siècle environ avant Bhavya et Siddhasena, on trouve déjà dans le Vākyapadīya (VP) du grammairien Bhartronari (450-510?) et son autocommentaire (svavrtti - VPSV $)^{20}$ deux références aux trayyantavid (VPSV 2.22, p. 202.18 ${ }^{21}$ ) ou trayyantavedin (VP 3.3.72d), «ceux qui connaissent la Fin de la Triple [Science] [= le Veda]». Il est vrai que ces expressions ne renvoient pas nécessairement à une école ou un groupe de penseurs; la première de ces deux occurrences, dans l'autocommentaire à VP 2.22, oppose toutefois clairement les trayyantavid aux kșanikavādin (les «tenants de la momentanéité [des choses]», i.e. les bouddhistes ou une section d'entre eux - p. 202.17-18) et leur attribue l'idée que «le Soi Universel (viśvātman) apparaît dans une séquence (krama) sans jamais abandonner son unité (ekatvānatikramena $) »^{22}$,

pa ni rig byed mtha'ba ste; " "Vedānta" (rig byed mtha 'ba ste) signifie "l'accomplissement de la connaissance" (rig pa's mthar phyin pa)». Voir Qvarnström 1989: 101, n. 28, qui conclut justement: "The term "Vedânta" is then not defined in reference to the Upanișads, i.e. the final portion of the Vedas». Si cette conclusion parait a priori s'imposer, la présence d'expressions proches ou équivalentes (vedavād[in], trayyantavādin, etc.) chez d'autres auteurs de la même époque, qui interprètent clairement le terme trayyanta/veda/vedānta en référence à un corpus de textes (voir infra et section 2), laisse cependant penser qu'il pourrait s'agir-là d'une expression typique, interprétée de manière originale ou dissidente par l'auteur de la Tarkajvālā.

17. Voir Qvarnström 2003, qui remarque cependant: «The use of the term "Vedavāda" in describing (pre-Śankkara) Vedānta philosophy is noteworthy, if not unique, at least in comparison with the nomenclature employed by doxographies from the same period» (p. 576, n. 1).

18. Voir Wezler \& Motegi 1998: xxvii-xxviii. La date de composition proposée (680-720), considérablement plus tardive que celle (550) initialement établie par Frauwallner (1953: 287), s'appuie sur les références faites par l'auteur du texte à l'œuvre de Dignāga et à la Kāśikāvrttti, ainsi que sur son apparente ignorance de la pensée de Dharmakīrti, difficilement explicable si la Yuktidīpika avait été écrite après la fin du viI ou le début du vIII ${ }^{\mathrm{e}}$ siècle.

19. YD 18: aupanișadāh khalv eka ātmeti pratipannāh; «Comme on sait, ceux qui se réclament des Upanișad soutiennent que le soi est unique» (p. 174.20).

20. Quoique ce point soit encore sujet à débat parmi les spécialistes de Bhartrahari, je considérerai dans cette étude les kārikā et la vrtti sur les deux premiers kānda comme partie intégrante d'un même texte nommé Vākyapadīya et composé par Bhartrohari. L'hypothèse aujourd'hui privilégiée par ceux qui nient l'attribution de la vrtti au célèbre grammairien du v viècle est qu'elle aurait été composée par un proche disciple, soit tout au plus une cinquantaine d'années après l'achèvement du texte des $k \bar{a} r i k \bar{a}$. Cette hypothèse, si elle devait être vérifiée, serait donc de peu d'influence sur la chronologie des idées vedāntiques que je m'efforce de retracer ici.

21. La lecture trayyantavidām qu'on trouve dans les trois éditions de la vrttii (Éd ${ }^{1939-1940}$ p. 19.5-6; Éd ${ }^{1980}$ p. 50.5 ; Éd ${ }^{1983}$ p. 202.18) est en réalité le fruit d'une conjecture «muette» due au premier éditeur du texte, Cārudeva Śāstrī, adoptée simplement par les deux éditions subséquentes. L'unique manuscrit disponible pour cette portion de la vrtti (Madras, GOML n ${ }^{\circ} 5543$, p. 59.2) présente la lecture aberrante turyan tadvidām reportée en note par K. A. S. Iyer (Éd ${ }^{1983}$ p. 202, n. 9), elle-même le résultat d'une correction de la part du scribe (la lecture originale est malheureusement illisible sur les images dont je dispose).

22. VPSV 2.22: viśvātmany ekatvānatikramena kramapratyavabhāsatvam bhavati (Éd ${ }^{1939-1940}$ p. $19.5-6 ;$ Éd $^{1980}$ p. $50.5 ;$ Éd $^{1983}$ p. 202.18-19). 
une affirmation qu'on rapprochera sans peine de déclarations parallèles dans les traités vedāntiques de la même époque ${ }^{23}$. Plus claire encore est la mention par Bhartrohari, dans l'autocommentaire à VP 2.233 (p. 249.6), des trayyantavādin («Les partisans du Trayyanta»), une expression potentiellement équivalente au composé vedāntavādin rencontré un siècle plus tard chez Bhavya $^{24}$. Cette référence aux Écritures distingue le Vedānta d'autres courants philosophiques mentionnés dans ces mêmes sources, définis en référence à une figure tutélaire - les kāṇāda, "partisans de Kaṇāda», i.e. le Vaiśeșika (MHK 7.27, YD 18, p. 174.21), les ākșapāda, «partisans d'Akṣapāda», i.e. le Nyāya (YD 18, p. 174.21), etc. -, par leur méthode d'investigation - la Mīmāṃsā, peut-être le Vaiśeșika (MHK 7.28) - ou par leur statut religieux - les arhant, les «Saints», i.e. les Jaïna (YD 18, p. 174.21).

Il semble donc qu'on ne puisse simplement opposer, comme le fait Bronkhorst, un courant ancien «philosophique» à un courant «exégétique» plus tardif, la différence entre ces deux courants étant dans le recours plus ou moins exclusif fait à l'Écriture plutôt qu'au raisonnement. En effet, qu'ils fassent ou non appel aux concepts et méthodes de la Mīmāṃsā, deux éléments semblent unir les auteurs vedāntiques de toutes époques (si l'on excepte, bien entendu, le néo-Vedānta d'époque moderne): d'une part, leur doctrine de l'ātman, mentionnée par tous les auteurs évoqués jusqu'ici; de l'autre, leur recours constant au texte des Upanișad, un point sur lequel les plus anciens doxographes ne se sont d'ailleurs pas trompés. L'exemple le plus flagrant en est peut-être la brève doxographie, déjà mentionnée, de Siddhasena Divākara. Comme le montre bien l'étude de Qvarnström (2003), son bref exposé en trente-deux stances des doctrines du Vedānta n'est en effet guère autre chose qu'un tissu de références scripturaires empruntées pour la plupart à la Roksaṃhitā (livres 1 et 10) ou à la Śvetāśvataropanișad (ŚvU), dont il pourrait mimer jusqu'au mètre ${ }^{25}$. La même remarque vaut, quoique dans une moindre mesure, pour l'exposé du Vedānta qu'on trouve dans les dix-neuf premières stances du chapitre 8 des Madhyamakahrdayakārikā de Bhavya, où l'on remarque là encore une nette prééminence de la Śvetāśvataropanișad ${ }^{26}$.

23. Vrșabhadeva/Śrīvrșșabha, dont le commentaire au premier livre du Vākyapadīya pourrait dater du $\mathrm{VI}^{\mathrm{e}}$ siècle ou de la première moitié du vIII ${ }^{\mathrm{e}}$ siècle (sur les diverses hypothèses en présence, voir Iyer 1969: 44-45 et Ferrante 2013 : 135-136), emploie la même expression trayyantavid pour parler de ceux qui admettent l'existence d'un «Soi Suprême» (paramātman). Voir Sphuțākșarā (= Paddhati) ad VPSV 1.1 : tasya cāyam vivartaś caitanyam yat trayyantavidah paramātmety āhuh; «Et cette manifestation illusoire est celle de la conscience (caitanya), que ceux qui connaissent la Fin de la Triple Science nomment "Soi Suprême" (p. 11.29-12.6).

24. Voir les deux gloses par Vrșabhadeva du terme trayyanta dans VPSV 1.10 (p. 39.5) par les termes upaniṣad (Sphuțākșarā p. 39.11) et vedānta (ibid. 1. 14). Voir infra, section 2.

25. Selon l'hypothèse formulée par Upadhye (1971: 260) et acceptée par Qvarnström (2003: 577, n. 6).

26. Ainsi, par exemple, MHK 8.2 et 8.7 paraphrasent manifestement ŚvU 3.8 et 3.9 respectivement. Voir Qvarnström 1989: 62-68 et Qvarnström 2003: 577-578 (n. 6). Il est remarquable que le même passage de la Śvetāśvataropanișad (3.8) soit également paraphrasé dans la section de la Daśabhümika(sūtra)vibhāṣā attribuée à Nāgārjuna (préservée uniquement en traduction chinoise) résumant la doctrine «védique» de la libération (10.22). Voir le passage traduit dans Nakamura 1983: 159. Quoique l'attribution de ce traité à Nāgārjuna soit disputée (voir Ruegg 1981: 29, n. 67), 
Quant aux Vedāntin anciens eux-mêmes, leur recours à l'Écriture n'est pas moins explicite. Ainsi Gauḍapāda (entre 550 et $700 ?{ }^{27}$ ) a-t-il soin, dans les $k$ k. 2.11-12 de l' Āgamaśāstra (ĀŚ), de présenter sa doctrine de l'ātman comme «la certitude [émanant des énoncés/textes] du Vedānta» (vedāntaniścaya $-2.12 \mathrm{~cd}$ ). Que Gauḍapāda entende bien par vedānta un texte ou un ensemble de textes ${ }^{28}$ apparaît clairement d'un autre passage de l'Āgamaśāstra (2.31), où Gauḍapāda parle de ceux «qui voient clair dans les [énoncés du] Vedānta» (vedānteșu vicakșan [āh]]). Loin de négliger la Révélation, l'Āgamaśāstra fait d'ailleurs à la śruti un appel constant ${ }^{29}$, en discute longuement l'interprétation $^{30}$, et en paraphrase volontiers certains passages ${ }^{31}$. De manière un peu moins nette, Ādiśeșa ( $\mathrm{VI}^{\mathrm{e}}-\mathrm{VII}^{\mathrm{e}}$ siècle?), dans la dernière stance du Paramārthasāra, affirme avoir composé son traité «après avoir examiné la science [que constituent les énoncés] du Vedānta» (vedāntaśāstram vilokya - k. 87). Sans surprise, son commentateur Rāghavānanda (XvI siècle?) interprète le composé vedāntaśāstra comme un «groupe d'énoncés visant à communiquer un objet désiré qu'on ne peut saisir par la perception, l'inférence et les autres [moyens de connaissance valide]» (pratyakșānumānādyanabhigamyābhimatārthaprakāśanaparam vākyakadambakam). Son interprétation, sans doute anachronique, est cependant confortée par la rareté des occurrences du terme vedānta au singulier dans les textes de cette période ${ }^{32}$.

L'Écriture n'a donc pas revêtu un caractère moins central pour ces auteurs que pour les théoriciens plus tardifs. Loin de les négliger pour mettre en avant leurs propres spéculations, les premiers Vedāntins se réfèrent aux textes upanișadiques comme à une source fondamentale d'inspiration, qu'il ne s'agit certes pas encore de commenter ou d'analyser de manière systématique, mais qu'on peut néanmoins discuter, imiter, paraphraser et prolonger par une réflexion indépendante. Ce faisant, ils ne font d'ailleurs que perpétuer une tradition qui remonte aux Upanișad anciennes, dont certaines font déjà la louange de «ceux qui ont parfaitement compris le sens [qui fait l'objet de] la connaissance des [énoncés du] Vedānta» (vedāntavijñānasuniścitārthāh - MuU 3.2.6) et considèrent le Brahman comme «le «Suprême Secret du Vedānta» (vedānte paramam guhyam - ŚvU 6.22). Il n'est donc pas invraisemblable que les premiers textes vedāntiques proviennent d'un milieu comparable à celui dans lequel ont été composées, depuis l'époque immédiatement post-védique, les textes auxquels on a plus tard donné le nom d' «Upaniṣad».

l'existence d'une traduction de l'œuvre (Taishō 1521) par Kumārajīva († 409/413), probablement réalisée en 408 (voir Lamotte 1987: 76), confirme qu'il s'agit-là d'un texte datant au plus tard de la fin du IV siècle. L'hypothèse d'une traduction plus ancienne par Dharmarakșa (actif entre 265 et 313) fait par ailleurs dire à Lamotte (1987: 76) que l'œuvre «était déjà parvenue en Chine vers 265 p. C.». 27. Voir Bouy $2000: 21$.

28. Et non une école, comme le suggère l'interprétation du composé vedāntaniścaya par Bouy (2000: 137), qui traduit «la certitude du Vedānta».

29. Voir ĀŚS 2.3 (śrüyate), 2.12 (où l'on constate une réminiscence de ŚvU 4.10), 3.23 (śrutih), 3.24 (āmnāyāt), 3.25 (allusion à l'İśāvāsyopanișad), 3.26 (allusion à la Brhadāranyaka ${ }^{\circ}$ ), etc.

30. Voir ĀŚ 3.11 (référence directe à la Taittirīy $a^{\circ}$, nommée ici Taittirīyaka), 3.12 (référence directe à la Brhadāranyaka ${ }^{\circ}$ ), 3.14-16 (discussion de divers passages upaniṣadiques relatifs à la création).

31. Ainsi, Ā ́́ 2.20-28c s'inspire manifestement du Śatapathabrāhmaṇa. Voir Bouy 2000: 127.

32. Voir supra, note 4. 
Que représente cependant, pour ces premiers Vedāntins, la catégorie des «[énoncés du] Vedānta » (vedāntāh) ? Il est difficile de répondre à cette question du fait de l'absence quasi totale de réflexion herméneutique dans ces premiers traités. Si l'Āgamaśāstra semble bien les assimiler à une forme de Révélation (śruti/āmnāya), ce terme n'est à aucun moment explicité par Gauḍapāda, et le statut du texte révélé ne fait jamais chez lui l'objet d'une réflexion approfondie. Tous les commentaires sur les œuvres du Vedānta ancien qui nous soient parvenus datant $\mathrm{du} \mathrm{VIII}^{\mathrm{e}}$ siècle au plus tôt, on se tournera avec profit vers d'autres textes de la même époque traitant des mêmes sujets, quand bien même ils n'appartiennent pas au Vedānta stricto sensu.

\section{Arthavāda, pravāda, trayyanta: l'herméneutique vedāntique de Bhartroari}

Un témoignage important sur l'évolution des conceptions des Écritures brahmaniques avant les $\mathrm{VII}^{\mathrm{e}}$ et $\mathrm{VIII}^{\mathrm{e}}$ siècles nous est fourni par Bhartrhari. Quoiqu'il appartienne de plein droit à la tradition grammaticale pāṇinéenne, le Vākyapadìya constitue en effet, par sa richesse et son ancrage profond dans la tradition brahmanique, un point de vue précieux sur l'état de l'exégèse védique et vedāntique au $\mathrm{v}^{\mathrm{e}}$ siècle. Le principal enjeu pour notre propos est de comprendre quelle signification revêt pour le célèbre grammairien le terme trayyanta («la Fin de la Triple Science») qui apparaît à quatre reprises dans son œuvre, une fois de manière indépendante (VPSV 1.10, p. 39.5) et, comme on l'a vu (section 1), trois fois comme partie intégrante des composés trayyantavid $/{ }^{\circ}$ vedin $/{ }^{\circ} v a \overline{d i n}$. Ce terme fait-il référence au corpus textuel que nous nommons «les Upanișad»? Recouvre-t-il par ailleurs la catégorie des upanișad\%vedāntavākya telle qu'elle sera définie par les exégètes plus tardifs? Comment, enfin, Bhartrahari se positionne-t-il par rapport à ces textes ou à leur(s) auteur(s)? Ces problèmes, intimement liés, peuvent être abordés de deux points de vue, herméneutique et doctrinal, qu'on adoptera ici tour à tour ${ }^{33}$.

D'un point de vue strictement herméneutique, pour commencer, le caractère «védique» des textes que Bhartrhari désigne par le terme trayyanta fait manifestement problème pour ce dernier ${ }^{34}$. Toute connaissance humaine,

33. La question de l'usage par Bhartrhari du concept de trayyanta, essentielle pour comprendre le rapport qu'il entretient avec la tradition vedāntin, n'a à ma connaissance pas été abordée de front par les spécialistes du Vākyapadīya. On trouvera cependant d'importantes remarques sur ces sujets dans Aklujkar 1991 : 1-5, Houben 1995 : 293-294 et Aklujkar 2009: 55-57.

34. Notons que l'hésitation de Bhartrihari à inclure le/les trayyanta au sein du corpus védique n'est pas sans précédent dans la littérature brahmanique. Voir par exemple la stance $15.15 \mathrm{~cd}$ de la Bhagavadgīta: vedaiś ca sarvair aham eva vedyo vedāntakrd vedavid eva cāham $\|$; «Je suis [Celui] qui est enseigné par tous les Vedas, je suis l'auteur des [énoncés du] Vedānta et le connaisseur des Vedas ». Le commentaire de Śankara esquive la double difficulté posée par cette stance de son point de vue (distinction Veda/Vedānta, affirmation d'un auteur pour ce dernier) en glosant le composé vedāntakrd («L'auteur du/des vedānta») par vedāntārthasampradāyakrd («L'initiateur de la tradition [d'explication] de l'objet du/des vedānta»-Gītabhāşya p. 627.4). Plus proche de Bhartrohari, le Mahābhāṣya (paspaśá ${ }^{\circ}$ - vol. 1, p. 9.21) distingue déjà les quatre Veda (catvāro vedāh) de leurs auxiliaires (anga) et des enseignements ésotériques (rahasya) qui leur sont attachés. Voir aussi à ce sujet les passages de la Br̆hadāranyakopanișad cités infra, note 36. 
affirme-t-il en VPSV 1.10, dérive des membres primaires et secondaires (anga/upāinga) du praṇava (la syllabe oṃ) que sont «la Révélation, la Tradition, le Trayyanta, etc.» (śrutismrtitrayyantādi) $)^{35}$. Quelle que soit la valeur qu'on attribue à la particule ${ }^{\circ} \bar{a} d i^{36}$, Bhartrhari distingue ici clairement le/les Trayyanta(s) comme un ensemble textuel distinct de la Śruti et de la Smrti, ensemble que son commentateur Śrīvrș̣abha/Vrșabhadeva identifie avec «les Upaniṣad/les énoncés upanișadiques » (upaniṣadah - Sphuṭākșarā p. 39.11) ou encore «les [énoncés du] Vedānta» (vedāntāh-ibid. p. 39.14). Quelle valeur, cependant, tous ces termes ont-ils pour Bhartrhari et son commentateur?

Certains éléments de réponse à cette question nous sont fournis par la section immédiatement précédente du Brahmakāṇ da (VP 1.5-9), qui contient l'essentiel des positions de Bhartronari en matière d'exégèse védique. Dans cette section, le fameux grammairien établit une répartition du Veda (au sens large ${ }^{37}$ ) en trois catégories : la Śruti tout d'abord, divisée en ses différentes branches $(s \bar{a} k h \bar{a})(k .6)^{38}$, la Smrti qui en dérive et que transmettent les śișta sous forme écrite et non écrite ( $k .7)$, enfin une troisième catégorie qu'il nomme pravāda, les «opinions [philosophiques] »" ${ }^{39}$, qu'il fait dériver des portions non injonctives de la Śruti, les arthavāda (k. 8). Cette tripartition présente une similitude frappante avec la division des membres du pranava

35. VPSV 1.10: pranavāingopāngebhyaś ca śrutismrtitrayyantādibhyo vidyābhedāh prabhavanti samyagjāānahetavah, purușasamskārahetavaś ca; «Des membres primaires et secondaires du pranava - la Révélation, la Tradition, le Trayyanta, etc. - procèdent les différentes sciences (vidyā) qui sont les causes des connaissances correctes ainsi que du perfectionnement des hommes » (p. 39.5-6).

36. Selon Śrīvrșsabha, ${ }^{\circ} \bar{a} d i$ renvoie notamment aux «stances» (śloka) citées dans les Upaniṣad, qu'il distingue des énoncés upaniṣadiques (upaniṣad) proprement dits: ādiśabdāc chlokādayah, yad ucyate 'tad apy ete ślokāh 'iti; « «Par le mot ādi [sont désignées] les stances, dont on parle [dans les Upanișad lorsqu'il est dit] “À ce sujet, il y a ces stances” (tad apy ete ślokāh)» (Sphuțākșarā p. 39.11-12). Il ne m'a pas été possible de trouver la source exacte de l'expression tad apy ete ślokāh citée par Vrșabha. On trouve néanmoins dans les Upanișad anciennes plusieurs formules proches: athaișa śloko bhavati (BĀU 1.5.23), tad eșa śloko bhavati (BĀU 2.2.3, 4.4.6-7), tad ete ślokāh bhavanti (BĀU 4.3.11, 4.4.8), tad eșa ślokah (ChU 3.11.1, 5.2.9, etc.), tad apy eṣa śloko bhavati (TaiU 2.1.1, 2.2.1, 2.3.1, etc.). Il n'est pas impossible que Vrșabha, lorsqu'il distingue śloka et upanișad, s'inspire d'une liste fameuse qu'on rencontre à trois reprises dans la Brhadāranyakopanișad (2.4.10, 4.1.2 et 4.5.11), dont voici la première occurrence : asya mahato bhūtasya nihśsvasitam etad yad rgvedo yajurveda hāamavedo 'tharvāngirasa itihāsa h purānam vidyā upaniṣadah < < em : vidyopanișadah Éd> ślokāh sūtrāny anuvyākhyānāni vyākhyānāni; «C'est l'exhalaison de ce grand Être qu'est Rgveda, Yajurveda, Sämaveda, Atharvāngiras, chants épiques, purāna, sciences, upanișad, vers, sūtra, explications, commentaires» (texte et traduction: Senart 1934: 33). Il est d'ailleurs plausible qu'en disant ślokādi, Vrșabha ait à l'esprit les trois membres de cette liste qui viennent à la suite des upanișad et des «stances» (i.e. sütra, anuvyākhyāna, vyākhyāna). 37. Sur la distinction entre un concept «large» et un concept « restreint» du Veda (identifié dans ce second cas avec la Śruti) dans VP 1, voir Aklujkar 1991: 3-5.

38. Mis à part la mention d'une division du Rgveda (bahvrca) en quinze branches ou écoles (pañcadaśadhā) selon «certains» (eke - p. 27.4), exceptionnelle dans les listes dont on dispose (voir Renou 1947: 18-19), la répartition du Veda en ses différentes śákhā qu'on trouve au début de VPSV 1.6 (p. 27.3-4) est traditionnelle, et très probablement calquée sur celle de Patañjali. Voir Mahābhāṣya (paspaśá $\left.{ }^{\circ}\right)$ vol. 1, p. 9.21-22.

39. Aklujkar (1991: 2) interprète le terme pravāda comme «une variété théorique ou philosophique d'āgama» («a theoretical or philosophical kind of āgama»). On trouve dans le Vākyapadīya, à ma connaissance, une seule occurrence de l'expression tārkikapravāda; «les opinions des philosophes». Voir VPSV 1.41 (p. 98.7). 
en Śruti, Smrti et Trayyanta qu'on vient de rencontrer en VPSV 1.10, et pourrait à vrai dire lui être superposée si l'on acceptait d'identifier purement et simplement trayyanta et pravāda. Cette identification est-elle cependant justifiée, ou la catégorie du trayyanta doit-elle plutôt être considérée comme une forme spécifique d'arthavāda ${ }^{40}$ ?

Commençons par examiner la définition que donne Bhartrohari du pravāda dans cette section. Par-delà une similitude de surface liée à leur caractère généralement non injonctif, deux traits principaux distinguent le pravāda de l'arthavāda. Leur provenance, tout d'abord: si l'arthavāda, «énoncé révélé» (śrutivākya - p. 30.5), est partie intégrante du texte védique, il n'en va pas de même du pravāda, qui partage avec la Smrti son caractère «personnel» (pauruseya - ibid.) - autrement dit son origine humaine ${ }^{41}$ - et se base sur des distinctions conceptuelles propres à l'esprit humain (purușabuddhivikalpa - p. 30.6) ${ }^{42}$. Deuxièmement, leur fonction: en parfait accord avec la Mīmāṃsā (voir Mìmāṇsāsūtra 1.2.7 [1]), Bhartroari considère l'arthavāda comme un texte principalement voué à la louange (upastuti - p. 31.1) du sacrifice, par exemple l'Offrande de Nouvelle et Pleine Lune (darśapūrnamāsa - p. 33.3), ou d'un de ses éléments, comme l'emplacement de l'Autel du Feu (agnicayanasthāna -ibid.). Il est vrai que l'arthavāda peut parfois revêtir l'aspect d'un énoncé théorique, comme c'est le cas des trois énoncés cités en VPSV 1.8, dont on notera le caractère délibérément contradictoire: asad vā idam agra āsīt ( «Au commencement, tout n'était que Non-Être»-p. 30.7), nāsad āsīn no sad āsìt tama eva khalv idam agra āsìt ( «Il n'y avait ni Être ni Non-Être: au commencement, en vérité, tout n'était que Ténèbre»-p. 32.4), āpo vā idam agra āsìt («Au commencement n'étaient que les Eaux»-p. 33.2). Cette apparence d'énoncé doctrinal ne fait cependant que masquer la réelle fonction laudative de ces passages et leur subordination totale à l'injonction ${ }^{43}$. Il en va tout autrement du pravāda, sans rapport avec l'injonction et directement construit sur la base de ces arthavāda «d'allure» théorique. Contrairement à l'arthavāada, le pravāda enseigne un point de vue sur le réel, une doctrine (dualiste, non dualiste, etc.). À l'inverse des énoncés de la Smrti, dont ils partagent pourtant l'origine humaine, les pravāda sont «propres à chaque école philosophique» (prthaktīrtha ${ }^{\circ}$

40. Quoiqu'il ne s'en explique guère, Aklujkar (2009: 55) semble accepter l'identification du trayyanta au pravāda lorsqu'il définit les énoncés du trayyanta comme «des refontes de, ou des commentaires sur la Śruti» («recasts of or comments on the Śruti»), une définition sommaire, mais adéquate du pravāda. La position inverse est soutenue par Halbfass (1991: 150), qui considère quant à lui que, pour Bhartrohari, les Upanișad sont «associées de manière plus ou moins explicite aux arthavāda» («more or less explicitly associated with the arthavādas»).

41. Sur le caractère «impersonnel» (apaurușeya) ou «sans auteur» (akartrka) du Veda selon Bhartrohari, voir notamment VP 1.43a (akartrkam śāstram) et VPSV 1.43 (apaurușeyam [...] āmnāyam - p. 99.6).

42. Voir aussi VPSV 1.124: sarvapravādeșv āgamavākyānām pranetroarigraheña paurușeyatvam abhyupagamyate, vedavākyāni tu caitanyavad apaurușeyāṇi; «Toutes les opinions philosophiques sont personnelles, car [dans ce cas] on connaît l'auteur des énoncés traditionnels. Mais les phrases du Veda sont impersonnelles, à l'instar de la conscience» (p. 203.7-8).

43. Pour une bonne explication de ce point en relation au premier de ces trois exemples, voir la Sphuțākșarā p. 31.9-19. 
- VPSV 1.1, p. 12.6; 2.233, p. 249.7; tìrtha - VPSV 1.38, p. 96.1; prthak ${ }^{\circ}$ - VPSV 1.126, p. 205.2 $)^{44}$, ce qui permet à Bhartrarhari de parler des pravāda «des monistes et des dualistes» (ekatvinām dvaitinām ca - VP 1.8c) ou encore du "pravāda moniste» (ekāntatvapravāda-VPSV 1.8, p. 31.1-2). Leur principal trait distinctif est leur caractère multiple et mutuellement contradictoire: Bhartrhari parle ainsi souvent d' «opinions [philosophiques] divergentes » (bhinnapravāda, bhinn [āh] pravād [āh], pravādabheda - VPSV 1.8, p. $30.6 ; 1.103$, p. $169.4 ; 1.109$, p. 179.2; pravāāa bahudhā - VP 1.8d) ou au contraire de points suffisamment consensuels pour que puissent s'en accommoder «même les tenants d'opinions [philosophiques] divergentes» (bhinnānām api pravādinām - VPSV 1.41, p. 98.6), voire «toutes les opinions [philosophiques]» (sarvapravāda - VPSV 1.1, p. $4.1 ; 1.36$, p. $94.2 ; 1.124$, p. 203.7). Un dernier point sur lequel il convient d'insister est le caractère essentiellement erroné du pravāda, un aspect dont Bhartrorhari traite en particulier dans le second $k a \bar{a} n d a$ (VP[/SV] 2.233). Comme il le dit alors, les opinions des différentes écoles philosophiques «[ne] dépeignent [que] la méconnaissance» (avidyām anuvarnayanta $h^{45}$ - VPSV 2.233, $\approx$ p. 249.7; cf. VP 2.233b). Prenant appui, d'une part, sur des arthavāda dont il ne voit pas qu'elles se contredisent si on les prend au pied de la lettre et, d'autre part, sur ses propres conceptions (svavikalpa-VP 1.8b), chacun construit des opinions philosophiques qui ne sont que le reflet de son propre esprit. C'est, en d'autres termes, d'une méprise fondamentale sur la nature du texte védique que naissent les opinions des philosophes, dont Bhartroari reconnaît toutefois l'intérêt d'un point de vue purement pédagogique (voir VP 2.233-38 et infra). On le voit, les catégories bhartrohariennes du pravāda et de l'arthavāda sont toutes deux très différentes de celle des «énoncés du Vedānta/des Upanișad» (vedānta /upanișadvākya) que théoriseront quelque deux siècles plus tard Maṇdana Miśra et Śankkara. Pour ces derniers, comme on l'a vu (voir «introduction»), la catégorie des énoncés du Vedānta est une classe d'énoncés védiques énonçant un objet existant ou accompli (bhüta/siddha). Cet aspect assertif ou déclaratif, qu'ils partagent avec l'arthavāda, n'a par ailleurs rien d'une apparence: loin d'être de simples louanges du sacrifice, les upanișadvākya n'ont réellement d'autre but que d'enseigner la nature de l'Ätman/Brahman. De ce fait, ils occupent un rang fonctionnel comparable à l'injonction, et se voient à leur tour subordonner des arthavāda. Une identification du Trayyanta évoqué par Bhartroari à l'une ou l'autre des catégories herméneutiques qui lui sont familières (arthavāda, pravāda) via la notion «classique» d'upaniṣad se révèle donc impossible.

44. Sur l'interprétation du terme tīrtha dans ce contexte, voir le commentaire de Śrīvrș̣abha sur VPSV 1.1, qui donne l'exemple du Sāṃkhya (ya ete sāṃkhyādipravādāh - Sphuṭākșarā p. 12.23) et renvoie sur ce point à VP 1.8 (p. 12.24-25).

45. Lecture du manuscrit de Madras (p. 134.17 - sur ce Ms. voir supra, note 21), qui semble confirmée par la kārikā (VP 2.233b: avidyaivopavarnyate; «c'est l'ignorance qui est dépeinte»). L'édition de K. A. S. Iyer lit avidyām anuvartayanto («suivent/se conforment à la méconnaissance» - p. 249.7) mais ne note pas la variante, si bien qu'il peut s'agir aussi bien d'une conjecture que d'une simple erreur. Sur ce passage, voir aussi infra, note 54 . 
Si l'on se tourne, maintenant, vers les différents exemples de pravāda et d'arthavāda cités dans VPSV 1.8, l'examen révèle une situation tout aussi complexe. Il est en effet impossible d'identifier simplement les pravāda avec ce que nous nommons «les Upanișad», ou même avec les portions les plus récentes du corpus védique. Certes, les trois exemples d'arthavāda cités dans la svavrtti sont bien empruntés à la littérature védique ancienne, qu'il s'agisse de la Rkksamhitā (10.129.1-3 - p. 32.4) ou des Brāhmaṇa du Yajurveda Blanc ou Noir (Mādhyaṃdina-Śatapathabrāhmaṇa 6.1.1.1 - p. 30.7; Taittirīyabrāhmaṇa 1.1.3.5 - p. 33.2). La citation de la Roksamhitā est inexacte cependant, et l'on y décèle déjà une possible réminiscence de la Maitrāyanyyupanișad (5.2). La situation est encore moins claire pour ce qui est des pravāda. De la dizaine d'exemples d'«opinions [philosophiques]» dont Bhartrhari affirme qu'elles «prennent appui» (ni- $\left.\bigvee_{s}^{\prime} r i\right)$ sur ces trois arthavāda, trois seulement ont pu être identifiés jusqu'à présent ${ }^{46}$. Si l'on trouve bien parmi eux une citation littérale de l'Íśā $\bar{a}$ syopanișad (k. 5- p. 35.2-3) et une autre, quasi littérale, du Taittirīyāranyaka $\left(1.11 .5\right.$ - p. 32.8-9) ${ }^{47}$, la troisième citation (p. 32.6-9) est sans équivalent exact dans la littérature védique connue, et pourrait dériver indifféremment de la Roksaṃhitā (1.164.20), de la Śvetāśvataropaniṣad (4.6) ou de la Muṇ̣̂kopanișad (3.1.1), qui présentent toutes la même stance. Il est donc impossible, sur cette base, d'assimiler la catégorie du pravāda avec la littérature upanișadique prise dans son ensemble, et tout autant de définir cette dernière comme une classe particulière d'arthavāda.

La svavrtti sur VP 1.2 fournit un complément utile à ces observations sommaires. Bhartronari y mentionne quatre exemples d'énoncés «révélés» ( $\bar{a} m n \bar{a} t a)$ parmi lesquels on retrouve, entre autres, le premier exemple d'arthavāda cité en VPSV 1.8 (Mādhyaṃdina-Śatapathabrāhmaṇa 6.1.1.1 - p. 15.3-16.1) sous une forme légèrement plus développée et quasi identique au texte du Brāhmaṇa tel qu'il nous est parvenu. Ce parallèle semble corroborer l'hypothèse d'Aklujkar (1991: 13, n. 24c) selon laquelle l'adjectif āmnāta (p. 15.1) qui qualifie ces quatre énoncés renverrait spécifiquement à la Śruti. Or, comme il le remarque encore (ibid.), les deux premiers passages cités sont des citations de deux Upaniṣad en prose, la Brhadāranyaka ${ }^{\circ}$ (4.3.32 - p. 15.1 [citation approximative]) et la Chāndogy $a^{\circ}$, dont Bhartrorhari cite le fameux refrain sad eva somyedam agra āsìd ekam evādvitīyam; "Au commencement, mon enfant, était l'Être et lui seul, l'Un, sans second» (6.2.1, etc. - p. 15.1-2). La dernière citation (p. 15.2) traite de la division du pranava en trois parties et n'est pas sans rappeler l'univers de la Māṇ̣̂ūkyopanișad. Si elle n'a pu être identifiée,

46. S'il est certes regrettable qu'on ne puisse se faire une idée plus précise des sources textuelles consultées par Bhartroari, le fait qu'on puisse identifier au moins une partie d'entre elles me semble confirmer qu'il s'agit bien de véritables citations et non, comme le suppose Madeleine Biardeau (1964), de «l'énoncé par l'auteur de la vrtti de diverses opinions réelles ou possibles qui découleraient du texte cité» (p. 38, n. 2).

47. On notera le caractère «védique» de ces deux textes de notre point de vue (l'Īśāvāsyopanișad étant, comme on sait, la section finale de la Väjasaneyisaṃhitā), qui interdit de tracer la ligne de partage arthavāda/pravāda au sens de Bhartrahari sur le modèle de la distinction moderne entre Upanișad «védiques» et «non védiques». 
il pourrait néanmoins s'agir d'une réminiscence de la Maitrāyaṇı $\bar{\imath}^{\circ}$ (5.2), qui présente avec elle une similitude frappante malgré la divergence des thèmes.

Deux conclusions provisoires s'imposent à ce stade. Tout d'abord, il apparaît que rien ne correspond, dans le système herméneutique de Bhartrohari, à la catégorie textuelle des upanișad (vākya)/vedānta (vākya) telle qu'elle est théorisée par les Vedāntin plus tardifs, ou à celle des «Upanișad» telle que nous l'entendons aujourd'hui : on trouve des passages d'Upanișad mentionnés à la fois à titre d'arthavāda (et donc de passage révélé) et de pravāda (c'est-à-dire d'opinion humaine construite sur la base d'un texte révélé $)^{48}$. On peut malgré tout déceler dans les textes examinés jusqu'à maintenant une tendance à considérer les passages empruntés aux Upaniṣad en prose (Brhadāranyaka ${ }^{\circ}$, Chāndogya $^{\circ}$, Maitrāyaṇ $^{\circ}$ ) comme des arthavāda, alors que les stances des Upanișad métriques ( $\bar{I} s \bar{a} v \bar{a} s y a^{\circ}$, etc.) sont volontiers assimilées à des pravāda. L'examen du système herméneutique bhartroarien ne nous permet donc pas de préciser de manière certaine le sens du concept de trayyanta. Ce dernier ne semble en fait pas avoir eu pour Bhartrhari de fonction exégétique précise, et pourrait à vrai dire être plus descriptif que fonctionnel. Peut-être est-il cependant possible d'en préciser la teneur en examinant cette fois les doctrines que Bhartrhari prête aux trayyantavid et leur rôle dans l'économie du Vākyapadīya.

De ce point de vue, on ne peut qu'être frappé par l'extrême proximité entre les vues attribuées par Bhartrhari aux trayyantavid $/{ }^{\circ}$ vādin $/{ }^{\circ}$ vedin et la doctrine même du Vākyapadīya. En effet, la plupart (sinon la totalité) des thèses prêtées à ces penseurs - s'il s'agit bien d'un groupe de penseurs trouvent leur équivalent en tel ou tel point des kārikā ou de la svavrtti. On trouve ainsi tout d'abord assignée aux trayyantavid en VPSV 2.22 l'idée, déjà mentionnée, que "le Soi Universel (viśvātman) apparaît dans une séquence sans [jamais] outrepasser son unité (ekatvānatikramena)». Il est vrai que le terme viśvātman ( «Soi Universel») n'apparaît pas dans les kārikā du Vākyapadìya, et que sa seule autre occurrence dans la svavrtti (VPSV 1.1, p. 10.6) est dans une stance d'origine inconnue (stance $k h a$ dans l'édition de K.A.S. Iyer, p. 10.5-6). Bhartrhari exprime cependant en VPSV 1.2 une idée proche, cette fois en son nom propre, lorsqu'il affirme: «La forme, unitaire ou séparée, des modifications et de [l'entité] sujette à modification [= le Śabdabrahman], tout cela [se manifeste] sans [jamais] outrepasser

48. Ce point semble avoir été négligé par Aklujkar (1991), qui interprète comme suit les données textuelles que l'on vient d'examiner: «We do not have evidence that would allow us to assert that the Veda or śruti status of what we classify as the Upanișads was rejected or even significantly questioned by the Brahmanical thinkers of B[hartrhari]'s time. However, on the other hand, we have indications to the effect that the Upanișads did not attract attention as a separate (from the Brāhmaṇas) body of authoritative literature and did not enjoy the status of being the most important śruti for Brahmanical philosophers» (p. 3-4). La première de ces deux affirmations me semble reposer sur le présupposé discutable que «les Upanișads» forment déjà, à l'époque de Bharțhari, un ensemble homogène dont il aurait été possible de questionner le caractère d'autorité. Elle est en outre partiellement contredite par les exemples d'énoncés upanișadiques intégrés par Bhartrahari à la catégorie des pravāda. La seconde remarque (concernant le statut à part des textes upaniṣadiques au sein du Veda) est exacte si on la limite aux textes upanișadiques effectivement considérés comme révélés. 
l'unité (ekatvānatikrameṇa) de la nature originelle ${ }^{49}$. Si l'on rencontre assez fréquemment dans la svavrtti l'expression ekatvānatikrameña (voir VPSV 1.5 , p. $25.4 ; 1.28$, p. $83.4 ; 2.22$, p. 202.17) ou ses équivalents (abhedānatikrameṇa - VPSV 2.13, p. 198.15/avyatirekānatikrameṇa - VPSV 2.32, p. 207.7, etc.), la similitude entre cette thèse «transmise par l'Écriture» (āmnāta - p. 15.1) et celle qu'il attribue dans le second kāṇda aux trayyantavid n'en est pas moins manifeste.

La même remarque vaut pour la mention des trayyantavedin dans le Sambandhasamuddeśa (VP 3.3.72), unique allusion possible aux «Vedāntin» dans les kārikā du Vākyapadīya. L'idée principale qui leur est attribuée est la suivante: le réel (satya) est un objet (artha) indivis au sein duquel l'esprit distingue artificiellement $\left(v i-\bigvee_{k l} l p\right)$ les trois éléments constitutifs d'un acte de connaissance que sont le connaisseur (draștro, l'objet connu (dr'śya) et l'acte de connaître (darśana) lui-même. Or, comme le remarque Helārāja ( $\operatorname{Pr} \operatorname{Pr} 1$, p. 175.17), cette idée a un équivalent exact dans le Brahmakāạda, plus précisément en VP 1.4, qui traite de la coïncidence au sein du Śabdabrahman des trois aspects que sont le sujet de l'expérience (bhoktr), son objet (bhogya) et l'expérience (bhoga) elle-même ${ }^{50}$. Un parallèle plus clair encore d'un point de vue terminologique nous est fourni par VP 3.2.14 (Dravyasamuddeśa), où Bhartrahari distingue au sein d'un réel (satya - VP 3.2.11a) unique (eka) et indivis (na bhidyate - VP 3.2.11d) les quatre aspects que sont le connaisseur (draștro), l'objet connu (dr'śya), l'acte de connaître (darśana) et son motif (darśane prayojanam). Sans faire nécessairement de Bhartrahari un «Vedāntin» stricto sensu, comme on l'a parfois affirmé ${ }^{11}$, ces deux exemples montrent en tout cas que certaines des positions qu'il défend coïncident avec celles qu'il attribue par ailleurs aux trayyantavid $/{ }^{\circ}$ vedin.

Le cas de VP(SV) 2.233-238 est plus complexe, puisqu'il ne s'agit plus d'une simple allusion à un point de doctrine: c'est cette fois toute une réflexion sur les modes d'accès à la connaissance (vidyā) et la validité provisoire des sciences (śāstra) qui se trouve placée sous l'égide des trayyantavādin, les

49. VPSV 1.2: yā̄ad vikāravikārivișayam ekatvarūpam prthaktvarūpam vā, sarvam tat prakrtyekatvānatikramena $($ p. 14.7-15.1).

50. VP 1.4 : ekasya sarvabïjasya yasya ceyam anekadhā $\mid$ bhoktrbhoktavyarüpena bhogarūpena ca sthitih $\| ;$ «Cet Un, qui tient toutes choses en germe et qui se présente sous de multiples formes: celle du sujet qui éprouve, celle de la chose éprouvée et celle de l'expérience elle-même» (traduction: Biardeau 1964: 31). Helārāja ne mentionne pas directement VP 1.4 dans son commentaire à VP 3.3.72, où il se contente de rapprocher la stance du Sambandhasamuddeśa du Brahmakānḍa en général. Voir PrPr1 ad VP 3.3.72: ... ity upapāditam brahmakānde vistarata iti tata evāvadhāryam; «Cela a été démontré en détail dans le Brahmakānda, qu'on s'y réfère donc!» (p. 173.17). Les deux stances en question (VP 1.4 et VP 3.3.72) sont cependant citées côte à côte par Helārāja dans son commentaire à la stance 14 du Dravyasamuddeśa $(\operatorname{PrPr} 1$ p. 117-118). Sur le possible arrière-plan upanișadique de ces passages, voir Houben 1995: 294.

51. Voir par exemple les remarques de Nakamura (2004: 457-459), qui fait de Bhartrhari «un philosophe du Vedānta» («a Vedānta philosopher» - p. 457) et même «une figure importante dans l'histoire de la philosophie vedāntique ancienne» («an important figure in the history of early Vedāntic philosophy»-ibid.). L'idée que «la position de Bhartrohari est adoptée telle quelle et considérée avec faveur par Vācaspati Miśra et Mādhava» («Bhartrhari’s position is adopted and approved as it stands by Vācaspati Miśra and Mādhava» - p. 458) me semble en particulier clairement excessive au vu des matériaux présentés. 
«partisans du Trayyanta $»^{52}$. Il est difficile, en l'absence de tout commentaire, de décider quelle part exactement des thèses développées dans cette section Bhartrohari attribue aux «Vedāntin», une tâche que ne facilite pas la transmission très lacunaire de la vrtti ${ }^{53}$. Sans doute doit-on y inclure celle qu'énonce la première phrase de VPSV 2.233, selon laquelle les diverses opinions philosophiques ( pravāda) ne sont qu'autant de moyens de donner accès (prati $\bigvee_{p a d^{\text {caus }}}$ ) à la connaissance (vidya $)$ et doivent leurs divergences au fait qu'elles ne dépeignent que la méconnaissance $(a v i d y \bar{a})^{54}$. De même, l'idée développée dans le même paragraphe (p. 249.12-14/Ms. p. 135.9) selon laquelle tout discours sur la réalité (tattvavyavahāra) se fait «à l'aide de réalités inexistentes» (asatyaih [...] tattvaih) - les pots et autres entités délimitées par leur position dans le temps et l'espace -, qui semble en être une conséquence directe. La conclusion célèbre du passage (VP 2.238b), qui assimile les divers moyens d'accès (upāya) à la connaissance aux «câlineries qu'on fait aux enfants» (bālānām upalālanāh $)^{55}$ n'est elle-même pas sans rappeler certains textes vedāntiques de la même époque ${ }^{56}$. Il est donc possible qu'on doive également considérer comme «vedāntique» aux yeux de Bharţ̌hari la réfutation de toute relation réelle de causalité - ce «processus miraculeux» (adbhūt [ā] vrtti[h]]), comme nous dit la vrtti (VPSV 2.234, p. 249.26-27) -, qui fournit à cette philosophie de la connaissance son fondement ontologique, et forme le cour de VP(SV) 2.23457. Peut-être convient-il enfin de lire dans la sentence finale asatye vartmani sthitvā tatah satyam samīhate ( Ayant erré sur le chemin du faux, ils se dirigent de là vers le vrai»-VP 2.238cd), qui a tout l'air d'un pastiche de formule upanișadique, un autre emprunt au «Trayyanta». Si c'est bien le cas, les parallèles avec le reste du Vākyapadìya sont légion:

52. Voir VPSV 2.233 : iha sarveșv eva śāstreșu trayyantavādino manyante; «À ce sujet, les partisans du Trayyanta considèrent, à propos de toute science sans exception, [ce qui suit]» (p. 249.6; Ms. p. 134.16 [voir note suivante]).

53. Dans le commentaire qui accompagne sa traduction de VP 2.233, Iyer note simplement: «The $V r t t i$ here is not at all clear and that is a great pity because one would very much like to know what, according to the Vrtti, Bhartrari means by Avidyā and Vidyā here» (Iyer 1977: 102). De fait, le texte de VPSV 2.233-238 imprimé dans l'édition qui lui est attribuée (Éd ${ }^{1983}$ p. 249-250) nécessite d'importants remaniements. Je cite ici les pages de cette édition, la seule disponible pour cette partie du texte, et note «Ms.» les lectures de l'unique manuscrit conservé pour cette portion de la svavrtti (voir supra, note 21).

54. VPSV 2.233: sarvaśaktim artham utprekșayā pravibhajyāvidyām anuvarnayanto $<\mathrm{Ms}$. : anuvartayanto Éd> vidyāpratipādane prāyeña prthaktīrthapravādāh pratāyante; «C'est après avoir divisé par l'imagination l'objet [unique et] pourvu de toutes les potentialités que se déploient généralement les opinions ( pravāda) propres à chaque école philosophique, qui [ne] dépeignent [que] la méconnaissance (avidyā), en vue de l'accès à la connaissance (vidyā)» (p. 249.6-8; Ms. p. 134.16-19). 55. Lecture du Ms. de la svavrtti (p. 137). L'édition critique des kārikā par W. Rau (1977) lit bālānām upalāpanāh («des babillages enfantins»?).

56. Voir par exemple l'Āgamaśāstra (3.15), qui parle des diverses descriptions scripturaires de la création (srști) comme d'autant de «moyens de parvenir» (upāyah [...] avatārāya) à la compréhension de la non dualité, qu'il convient de ne pas prendre littéralement. Sur ce śloka, voir également les remarques éclairantes de Christian Bouy (2000: 156-157).

57. L'idée générale du passage est bien résumée en VP 2.234: anibaddham nimitteșu nirupākhyam phalam yathā $\mid$ tathā vidyāpy anākhyeyā śāstropāyeva laksyate \|; "Tout comme l'effet, inexprimable, est sans lien [réel] avec ses causes, de même la connaissance, inexplicable, est connue elle aussi comme ayant les sciences pour moyen d'accès». Sur la production (et la destruction) de l'effet comme «processus miraculeux» (adbhutā vrtti), voir aussi VP 3.3.81, 3.9.17 et 26, et les remarques de Houben 1995 : 301-302. 
le Brahmakāṇạa (1.1-4) ne décrit-il pas déjà ce «Brahman éternel» (brahma śāsvatam - VP 2.237d/anādinidhanam brahma - VP 1.1a), «au-delà de [toute] distinction conceptuelle» (vikalpātītatattva-VPSV 2.233, p. 249.11/ sarvavikalpātītatattva - VPSV 1.1, p. 1.3), «possédant toutes les potentialités» (sarvaśakti - VP2.233, p. 249.6/samāviștam sarvābhih śaktibhih -VPSV 1.1, p. 1.3), etc.? On a par ailleurs déjà évoqué le caractère mutuellement contradictoire des opinions philosophiques ( $\operatorname{rava\overline {d}} a$ ), incapables de saisir le réel de manière adéquate, à propos des réflexions herméneutiques de VPSV 1.8, dont $\mathrm{VP}(\mathrm{SV})$ 2.233-238 pourrait constituer le pendant sur le plan doctrinal.

Ainsi, loin de désigner une «école» dont il chercherait à se distinguer, ou encore de dévoiler une doctrine qui serait fondamentalement différente de la sienne, les trois références aux tenants/connaisseurs du/des Trayyanta(s) dans le Vākyapadīya apparaissent comme parfaitement intégrées à l'exposé doctrinal de Bhartrhari. Les sujets abordés sont toutefois parmi les plus généraux (la nature du réel, l'accès à la connaissance, la relation entre sujet connaissant et objet connu) et ne concernent jamais les questions linguistiques proprement dites. Par l'appel répété au/aux Trayyanta(s), il semble donc que Bhartrahari ait cherché avant tout à inscrire ses réflexions linguistiques dans un cadre traditionnel plus large et à épouser, comme l'avait fait avant lui Patañjali, l'une des principales tendances du brahmanisme orthodoxe de son temps. Le terme trayyanta recouvre dès lors pour lui un ensemble de textes traditionnels à portée théorique et révérés comme tels (dont rien ne laisse d'ailleurs penser qu'il s'agisse à cette époque d'un corpus $\operatorname{clos}^{58}$ ), mais que ne permet de saisir pleinement aucune des catégories herméneutiques dont il dispose. Cette difficulté à circonscrire le domaine du/des Trayyanta(s) est révélatrice d'un paradoxe qui pourrait caractériser l'exégèse brahmanique du $v^{\mathrm{e}}$ siècle dans son ensemble: comment en effet fonder un discours à portée théorique sur un texte, le Veda, dont la visée est considérée comme exclusivement normative? Toute doctrine quelle qu'elle soit n'est-elle pas de ce fait condamnée à n'être qu'une «opinion» (pravāda) parmi d'autres, inapte à représenter le réel tel qu'il est? Tout effort pour établir une pensée philosophique «védique» n'est-il pas dès lors voué à l'échec, puisqu'il doit se résoudre soit à s'enfermer dans des représentations multiples et qui se valent toutes (puisqu'elles ne font que refléter les catégories de la pensée humaine), soit à chercher son fondement dans un texte dont l'intention est toute différente? En d'autres termes, on a peine à expliquer, partant des prémisses qui sont celles de Bhartrihari, que puisse seulement exister un «partisan du Trayyanta»! C'est ce paradoxe que s'efforcera de résoudre l'exégèse dans les siècles qui suivent, par la création d'une catégorie herméneutique inédite, et par l'intégration de l'effort spéculatif attribué par Bhartrohari à l'esprit humain au Veda lui-même ${ }^{59}$.

58. Comme le remarque justement Aklujkar (2009: 55), l'assimilation (partielle, comme on l'a vu) des Upanișad aux pravāda - donc à des productions de l'esprit humain - autorise en théorie à composer indéfiniment de nouvelles Upanișad et à les considérer comme partie intégrante de la littérature brahmanique orthodoxe, ce que l'intégration d'un nombre défini d'Upaniṣad au corpus védique à époque plus tardive rendra plus difficile.

59. Ce paradoxe herméneutique est particulièrement visible dans la section initiale du Brahmakāṇ̣a, qui manifeste certaines tensions entre sa section métaphysique initiale (VP 1.1-4) et 


\section{Les «énoncés du Vedānta»: naissance d'une catégorie exégétique}

L'absence remarquable de la catégorie des vedānta(vākya)/upaniṣad (vākya) chez Bhartrohari et les difficultés qui s'ensuivent pourraient certes refléter une particularité de son système, voire trahir une connaissance approximative de la Mīmāṃsā de la part du célèbre grammairien. Un bref tour d'horizon de la littérature mīmāmssaka contemporaine suggère cependant que le Vākyapadīya est au contraire tout à fait représentatif des tensions qui animent la pensée exégétique brahmanique de son temps, et en annonce certaines évolutions structurelles. À l'absence totale de réflexion herméneutique dans la collection des Brahmasūtra correspond en effet, dans les Mìmāmsāāsutra (MīSū), une division du Veda en deux catégories héritée des sütra du rituel (voir Gonda 1977: 502): les mantra («formules») et les brāhmaṇa («explications»). Cette dernière catégorie est elle-même divisée en deux sous-catégories: les vidhi/codanā («injonctions») et les arthavāda («gloses explicatives», «discours sur les choses»), qui regroupent tous les passages du Veda à caractère non injonctif à l'exception des mantra (narrations, étymologies, spéculations, etc.). Cette classification est en outre considérée comme exhaustive, puisque le Mīsū 2.1.32 [7], qui donne la définition du mantra, est suivi par une définition entièrement négative du brāhmaṇa en MīSū 2.1.33 [8]: śeșe brāhmaṇaśabdah ; «Le mot brāhmaṇa [s'applique] au reste $»^{60}$. À moins d'un remaniement majeur, l'unique possibilité pour situer les énoncés upaniṣadiques par rapport à cet ensemble très structuré, centré sur l'injonction, est donc soit de les inclure comme une sous-catégorie de brāhmana (confondue ou non avec les injonctions ou les arthavāda), soit d'en faire une catégorie d'énoncés non védiques, trahissant une origine humaine. C'est ce dilemme que reflète chez Bhartrohari l'oscillation entre arthavāda et pravāda pour rendre compte de ce qu'il nomme «Trayyanta $»^{61}$.

\footnotetext{
la section exégétique qui lui succède (VP 1.5-9). Il est par exemple contradictoire d'affirmer d'une part, comme le fait Bhartrohari à propos de sa doctrine de la manifestation en VPSV 1.2, qu'elle est «transmise par l'Écriture» (āmnāta), et de soutenir d'autre part en VPSV 1.8 - à propos précisément de l'exemple védique cité à l'appui (asad vedam agra āsìt, etc.) -, que sa seule fonction est de faire la louange (upastuti) de l'emplacement de l'Agnicayana!

60. Voir aussi Śābarabhāṣya ad MīSū 2.1 .33 [8]: atha kiṃlakșanam brāhmanam? mantrāś ca brāhmaṇạ ca vedah. tatra mantralakșaṇa ukte pariśeșasiddhatvād brāhmanalakșanam avacaniyam. mantralakșanavacanenaiva siddham; "À présent, quelle est la définition du brāhmaṇa? Le Veda, ce sont les mantra et les brāhmaṇa! À ce sujet [on répond qu']une fois énoncée la définition du mantra, on n'a pas besoin d'énoncer une définition du brāhmaṇa, car cette dernière est établie par élimination (pariśeșa). [En d'autres termes,] elle est établie par le simple énoncé de la définition du mantra [dans le précédent sūtra]» (vol. 2, p. 421.5-7).

61. Notons que la difficulté à intégrer un discours à portée spéculative et sotériologique au Veda ainsi conçu fut utilisée à des fins polémiques par certains auteurs bouddhiques de la même époque, qui cherchèrent par ce biais à nier l'existence d'un enseignement sur la délivrance du saṃsāra au sein des Écritures brahmaniques. C'est notamment le cas de l'auteur (Nāgārjuna?) de la Daśabhümika(sūtra) vibhāṣā (III'-IV siècle? - voir supra, note 26), dont d'importants passages sont traduits dans Nakamura 1983: 158-164 (voir en particulier p. 161). Après avoir rappelé la distinction canonique du Veda en mantra, vidhi et arthavāda, l'auteur nie ainsi qu'aucune de ces trois catégories contienne un enseignement sur la délivrance, «car le désir des joies de ce monde, le fait de brûler de l'herbe Kuśa et la récitation de formules sacrées n'ont rien à voir avec la vraie sagesse» («because the lusting after worldly pleasure, the burning of Kuśa grass and the recitation
} 
Cette difficulté n'est cependant pas clairement visible chez les plus anciens auteurs de la Mīmāṃsā. La notion même d'upanișad(vākya), vedānta (vākya) ou trayyanta(vākya) est étrangère à Śabara (IV ${ }^{\mathrm{e}}-\mathrm{v}^{\mathrm{e}}$ siècle?), l'auteur du premier commentaire sur les Mìmāms āsūtra qui nous soit parvenu. Il arrive certes que Śabara mentionne un passage upanișadique à l'appui de telle ou telle thèse philosophique. Cette pratique - en soi surprenante - est cependant limitée à la section finale de son commentaire sur le MīSū 1.1.5 (vrttikāragrantha), consacrée à l'ātman, où l'on trouve une dizaine de citations de la Brhadāranyakopanișad ${ }^{62}$ introduites le cas échéant comme des brāhmana ${ }^{63}$. La notion exégétique de vedānta(vākya) est probablement encore inconnue de Prabhākara (VI ${ }^{\mathrm{e}}-\mathrm{VII}^{\mathrm{e}}$ siècle?), l'un des deux principaux commentateurs sur le Śābarabhāṣya. En témoigne le passage de la Brohatì (1.1.2) où le fameux docteur de la Mīmāṃsā discute la contradiction apparente entre sa conception de l'objet du Veda, l'« obligation» $(k \bar{a} r y a)$ rituelle, et la présence dans le texte sacré de passages non injonctifs, n'instituant a priori aucune obligation. Les deux seules catégories textuelles mentionnées par Prabhākara sont alors les mantra et les arthavā $d a^{64}$. S'il avait eu connaissance du problème similaire posé par les énoncés du Vedānta, il semble peu vraisemblable qu'il ne les ait pas évoqués à cet endroit de la Brothat̄, qui allait devenir pour toute la lignée prābhākara ultérieure le lieu privilégié d'une confrontation avec la tradition vedāntin ${ }^{65}$.

of formulas have nothing to do with true wisdom»-p. 161). Quoique le contexte soit clairement hostile au brahmanisme, la définition des trois catégories d'énoncés à l'aide d'exemples ne commet aucun contresens majeur, et reflète sans aucun doute la conception du texte védique dominante en milieu brahmanique à l'époque de la composition de la Vibhāṣa . La difficulté dénoncée par son auteur me semble par ailleurs correspondre de manière assez précise à celle que rencontrera plus tard Bhartṛhari, à savoir celle d'inscrire un discours théorique « védique» dans le cadre herméneutique hérité de la tradition ritualiste, relayée par la Mīmāṃsā.

62. Voir Śábarabhāşya ad MīSū 1.1.5: F 54.22-23 (BĀU 2.4.12/ 4.5.13), F 56.13 (BĀU 4.5.15), F 56.13-14 (BĀU 4.5.14), F 58.8 (BĀU 4.3.6), F 58.9-10 (BĀU 4.2.4/4.4.22/4.5.15), F 58.11-12 (BĀU 4.3.9/4.3.14), F 58.14 ( $\approx \mathrm{B} \bar{A} U$ 3.9.26/4.2.4/4.4.22/4.5.15), F 60.18-19 (BĀU 4.5.14), F 60.2021 (BĀU 4.5.14). Voir aussi Garge 1952: 139.

63. Voir Śābarabhāṣya ad MīSū 1.1.5: F 54.22 (athāsminn arthe brāhmanam bhavati), F 56.12 (athāpy asminn arthe brāhmanam bhavati), F 58.7 (athāsminn arthe brāhmanam bhavati), F 58.9 (atrāpi brāhmanam bhavati), F 58.11 (atrāpi brāhmanam bhavati), F 58.13-14 (atrāpy upāye brāhmaṇam bhavati). On notera l'accord de Śabara avec Bhartr̆hari, qui cite lui aussi un extrait de la Brhadāranyakopaniṣad aux côtés d'un passage du Śatapathabrāhmaṇa qu'il qualifie explicitement d'arthavāda (voir supra, section 2).

64. Voir Brhatī 1.1.2: yadi kārya eva cārthe vedasya prāmānyam, kathạ tarhi bhūtādyarthāvagatir mantrārthavādeșu; «Si le Veda n'est un moyen de connaissance valide que [lorsqu'il porte] sur un objet obligatoire, comment se fait-il qu'on saisisse un objet existant, etc. (bhütādi) dans le cas des mantra et des arthavāda?» (C 18.1-2/M 23.5-6).

65. Voir par exemple la Rjuvimalā (1.1.2) de Śālikanātha (autour de 900) : katham punaḥ kāryarūpa eva < eva $\mathrm{M}: \varnothing \mathrm{C}>$ vedārthạ, yāvatā vedāntānām siddha evārthạ 'vijñānam ānandam brahma'iti pratīyate; "[Objection:] mais comment l'objet du Veda pourrait-il avoir exclusivement la forme d'une obligation, puisqu'on saisit un objet réalisé (siddha) dans le cas des [énoncés du] Vedānta, [par exemple] "Le Brahman est conscience, félicité” (BĀU 3.9.28) ?» (C 16.9-10 / M 20.15-17). Voir, sur le même sujet, le Nayaviveka (1.1.2) de Bhavanātha (XI siècle ?): $n a$ kāryam eva vedārthah, 'ānandạ̣ brahma' ityevamādivedāntavākyānām siddhārthāvagateh ; «L'obligation [rituelle] ne saurait être à elle seule l'objet du Veda, car on saisit un objet réalisé (siddha) dans le cas des énoncés du Vedānta, par exemple "Le Brahman est conscience, félicité" (BĀU 3.9.28)» (p. 38.7-8). Notons cependant qu'en deux endroits de son œuvre, Maṇana Miśra fait manifestement référence au passage de la Brhatī cité plus haut (note précédente), en y ajoutant 
Le premier Mīmāṃsaka à distinguer formellement les upaniṣad des arthavāda semble donc être Kumārila ( $\mathrm{VI}^{\mathrm{e}}-\mathrm{VII}^{\mathrm{e}}$ siècle?), qui n'en remet pas pour autant en cause la primauté fonctionnelle de l'injonction ${ }^{66}$. Kumārila attribue ainsi deux fonctions aux upanișad, qui dépendent toutes deux de la connaissance du soi (ätmajñ̄ana) qu'elles communiquent principalement. Selon ses déclarations les plus fréquentes, les upanișad ont pour but de «faire connaître l'agent [du sacrifice]» (kartrpratipādana), une opération accomplie selon lui «pour le bénéfice du sacrifice» (kratvartha), non pour celui de la personne qui connaît (purușārtha $)^{67}$. En prenant connaissance de sa propre identité comme d'une substance distincte du corps, l'agent du sacrifice devient capable de concevoir qu'il jouira des fruits du sacrifice dans l' ' autre monde» (paraloka) et trouve ainsi une motivation suffisante à l'accomplissement du rite ${ }^{68}$. Un passage du Tantravārttika bien étudié par Mesquita (1994: 460-464) ${ }^{69}$ laisse cependant penser que, pour Kumārila, se juxtapose à cette première fonction, subordonnée à l'injonction sacrificielle, une seconde fonction, cette fois directement sotériologique. La connaissance

toutefois la mention des upanișad. Voir Vidhiviveka 29 (svavrtti) : asamañjasam etat - yadi kāryarūpa eva vedārthaḥ, katham tarhi mantrārthavādāḥ sopanișatkāh - ity àsan்kyāvatāritam codană hìti, yasmād bhūtādikam artham codanaiva gamayati; " Il est incorrect d'introduire [comme le fait Prabhākara la phrase du Mīmāmsābhāşya 1.1.2 commençant par] codanā hi («Car l'injonction [fait connaître un objet passé, présent et futur]») par le doute suivant: "si l'objet du Veda a exclusivement la forme d'une obligation, comment donc [cela est-il possible dans le cas des] mantra et des arthavāda, ou encore des upanișad"? En effet, [Śabara affirme] précisément que l'injonction fait connaître un objet passé[, présent ou futur]!» ( $\mathrm{S}^{\mathrm{D}}$ 553.5-8 [ $\approx \mathrm{M}$ 279.3-5/ G 199.2-4]); Brahmasiddhi 2.1 (svavrtti - introduction): tathā ca katham tarhi mantrārthavāāāh sopaniṣatkā ity āśankkya codanā hi bhūtam bhavantam ityādy uktam; «Et ainsi, [la phrase du Mīmāṃsābhāṣya 1.1.2 commençant par] codanā hi bhūtam bhavantạ̣ ( Car l'injonction [fait connaître un objet] passé, présent [et futur]») présuppose le doute suivant: "comment donc [est-il possible que le Veda ait pour objet une obligation dans le cas des] mantra et des arthavāda, ou encore des upanișad?» (p. 74.7-8). En l'état actuel des recherches sur la Brhatī, il est impossible de déterminer si Maṇdana cite ou paraphrase simplement Prabhākara. On ne peut cependant exclure que la mention des upanișad par le grand Vedāntin ne soit pas un ajout de son cru, et reflète plutôt un état du texte de la Brhatī plus ancien que celui dont témoignent ses deux éditions modernes.

66. Voir en particulier Tantravārttika 1.2.7 (passage cité, note suivante) et 1.3.2 (vol. 2, p. 80.22 et p. 81.17). Voir aussi Halbfass 1991 : 192, n. 105. La présence, dans les deux derniers cas, des termes arthavāda et upanișad au sein d'un composé copulatif (lokārthavādopanișad/upanișadarthavāda ${ }^{\circ}$ ) ne laisse planer aucun doute sur la distinction des deux concepts dans l'esprit du grand penseur de la Mīmāṃsā. Dans le second de ces trois passages, Kumārila place les upaniṣad aux côtés de l'expérience (loka) et des arthavāda parmi les fondements possibles de la science du raisonnement (tarka), alors que dans le troisième il fait des arthavāda et des upanișad la source (non reconnue) de certaines doctrines bouddhistes: idéalisme (vijñānamātra), momentanéité (kṣanabhañga), absence de soi (nairātmya), etc. Notons également l'usage par Kumārila de la locution evam hy upanișatsūktam («En effet, voici ce qui est dit dans les Upanișad») pour introduire une citation littérale de la Chāndogyopanișad (7.1.2). Voir Tantravārttika 1.3.7 (vol. 2, p. 123.8 [= Harikai 2009]). 67. Voir Tantravārttika 1.2.7: etena kratvarthakartrospratipādanadvārenopanișadām nairākān̄kșyam vyākhyātam, «Ainsi, on a [aussi] expliqué en quoi les [énoncés des] Upanișad ne sont en attente [de rien] dans la mesure où ils font connaître l'agent [du sacrifice], [une opération accomplie] pour le bénéfice du sacrifice» (vol. 2, p. 12.12-13 [= Harikai 2007]). Voir aussi Ślokavārttika (Sambandhākșepaparihāra ${ }^{\circ}$ ) 102-104. Traduction: Mesquita 1994: 455.

68. Voir Tantravārttika 1.3.29: (...) tena vinā paralokaphaleșu karmasu pravrttinivróttyasambhavāt; "En effet, sans elle [= la connaissance du soi], il est impossible d'accomplir ou [au contraire] d'éviter d'accompir des actes dont les effets [se produiront] dans l'autre monde» (vol. 2, p. 227.13-14 [= Harikai 2011]).

69. Tantravārttika 1.3.29, vol. 2, p. 227.11-228.20. 
du soi sert ainsi en elle-même à obtenir une série de résultats bénéfiques à la personne qui connaît, mentionnés dans les Upaniṣad et dont le point culminant est «l'obtention du Soi Suprême» (paramātmaprāpti), autre nom $\mathrm{du}$ «non retour» (apunarāvrtti) de l'adepte dans le samsāara après la mort ${ }^{70}$.

Si plusieurs études (Mesquita 1994, Yoshimizu 2007) ont justement souligné la proximité de ces thèses avec celles du Vedānta, elles manquent cependant de remarquer combien Kumārila en reste éloigné d'un point de vue proprement exégétique. Si une fonction sotériologique indépendante est en effet bel et bien attribuée à la connaissance du Soi par les Upanișad, cette «autre voie» (bhinnamārga), comme la nomme Kumārila ${ }^{71}$, est définie de manière identique à la première (celle du sacrifice), à savoir par le biais d'une injonction. «Connais le soi!» : tel est, selon le docteur mīmāṃsaka, le message fondamental des énoncés upanișadiques. Ce point apparaît clairement à la lecture de l'exposé du Tantravārttika; non seulement Kumārila parle-t-il à deux reprises de «l'injonction de connaître» (jñānavidhāna - p. 228.15) ou de «l'injonction de connaître la réalité du soi» (ätmatattvajñānavidhāna - p. 227.17-18). Les exemples même d'énoncés upaniṣadiques cités à ce propos ont tous, sans exception, une forme injonctive: (...) so 'nveștavyah, so vijijñāsitavyah ( "C'est lui [= l'ätman] qu'il faut chercher, qu'il faut s'appliquer à connaitre»-ChU 8.7.1), mantavyo boddhavyah («Il faut le penser, le connaître»- $\approx \mathrm{B} \bar{A} \mathrm{U} 2.4 .5$ ), àtmānam upāsīta («C'est l'ātman qu'il faut méditer»-BĀU 1.4.15) ${ }^{72}$. Ces injonctions de connaître se voient alors subordonner un certain nombre d'autres énoncés upanișadiques, dont la fonction est de définir le but (phala) atteint par la connaissance du soi ainsi prescrite, et auxquels Kumārila refuse catégoriquement le statut d'arthavāda ${ }^{73}$. Deux fonctions sont donc reconnues aux upanișad par l'auteur du Tantravārttika: d'une part, l'énoncé d'une relation (sambandha) entre un certain acte (en l'occurrence, l'acte de connaître le soi) et un résultat escompté (phala) ${ }^{74}$, fonction que Kumārila attribue régulièrement à l'injonction ${ }^{75}$; d'autre part, la définition même de ce résultat - joies de ce monde (abhyudaya) ou Bien

70. Voir Tantravārttika 1.3.29, vol. 2, p. 227.22-23.

71. Tantravārttika 1.3 .29 , vol. 2, p. 228.18 .

72. Notons que c'est déjà sous la forme de l'injonction ātmā jñātavyah («Le soi est digne d'être connu») que l'hypothèse d'un enseignement védique sur la délivrance est abordée dans le Ślokavārttika (Saṃbandhākșepaparihāra $\left.{ }^{\circ} 103 a\right)$. La citation, dont je n'ai pu trouver la source, pourrait être un pastiche de BĀU 2.4.5 (ătma a [...] draștavyah). L'identification du passage comme BĀU 1.4.15 par Mesquita (1994: 455) semble en tout cas être une erreur.

73. Voir Tantravārttika 1.3.29: aprakaranagatatvenānaikāntikakratusambandhāc $<^{\circ}$ sambandhāc Harikai : 'sambandāsambandhāc Éd> ca nāñ̃anakhādirasruvavākyādiphalaśrutivad arthavādatvam; «Dans la mesure où [les énoncés sur le résultat escompté de la connaissance du soi] sont situés hors du contexte [immédiat de l'injonction sacrificielle], et puisque leur relation au sacrifice est inconstante, ce ne sont pas des arthavāda, au contraire d'énoncés révélés [énonçant] un résultat [escompté] (phalaśruti) tels que les énoncés sur l'onction [de beurre clarifié] (añjana) ou la sruva [= cuiller à oblation] faite de [bois de] khadira» (vol. 2, p. 227.3-4/Harikai 2011). La dernière partie du texte fait probablement référence au passage de la Taittirīyasaṃhitā cité par Śabara ad MīSū 4.3.1 [1] (vol. 5, p. 59.3-4), explicitement qualifié par ce dernier de phalārthavāda («arthavāda [énonçant] un résultat [escompté]») (ibid. p. 60.1): yasya khādirah sruvo bhavati chandasām eva rasenāva dyati sarasā asyāhutayo bhavanti (Taittirīyasamhitā 3.5.7.1).

74. Voir Tantravārttika 1.3.29, vol. 2, p. 227.18.

75. Sur ce point, voir David 2013: 276 et n. 12. 
Suprême (nihśrreyasa $)^{76}$ - hors de toute référence à un quelconque contexte sacrificiel.

L'étape finale de ce processus ne sera donc accomplie qu'avec la dissociation des énoncés upanișadiques de toute forme d'injonction, fût-elle une injonction de connaître le soi. Ce pas décisif, qui marque la distance entre l'herméneutique "vedāntisante» de Kumārila et celle du Vedānta proprement dit, est franchi par Maṇdana Miśra (660-720?), qui expose ses vues sur le sujet à deux reprises dans son œuvre, une première fois dans un long passage digressif du Vidhiviveka (désormais $\mathrm{ViV})^{77}$, une seconde dans le Niyogakānda de la Brahmasiddhi (désormais BS), dont l'indépendance des vedāntavākya constitue le thème principal. Limitons nous, pour les besoins du présent exposé, au premier de ces deux textes, qui présente la théorie sous sa forme la plus ancienne ${ }^{78}$. Le problème est cette fois clairement posé: comment concilier l'existence dans le texte védique d'énoncés prodiguant un enseignement salvifique sur la nature du soi - énoncés qui reçoivent pour la première fois leur appellation canonique de vedāntāh («[énoncés du] Vedānta $»)^{79}$ - avec le fait que le Veda a pour but de provoquer ou d'empêcher l'activité d'un auditeur? Ne convient-il pas de considérer la connaissance (pratipatti) du soi - qu'elle soit de nature verbale, méditative ou autre - comme l'activité minimale enjointe par de tels énoncés? À cette dernière hypothèse, d'inspiration probablement kumārilienne (quoique fortement marquée par la théorie de Prabhākara ${ }^{80}$, Maṇạana oppose un

76. Sur ce double but, voir Tantravārttika 1.3.29, vol. 2, p. 227.18 .

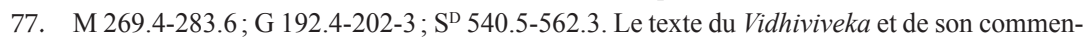
taire est cité, sauf exception, d'après l'édition critique de travail réalisée par Elliot M. Stern ( $\left.\mathrm{S}^{\mathrm{D}}\right)$. Cette édition n'ayant pas encore été publiée, référence est également faite aux deux éditions plus anciennes (1907 [M] et 1978 [G]). Je remercie E. Stern d'avoir bien voulu me communiquer cette version provisoire de son édition, actuellement en cours de révision.

78. Notons que, si le Niyogakānda de la Brahmasiddhi peut à juste titre être lu comme un développement des thèses initialement présentées dans le Vidhiviveka (voir Biardeau 1969: 86, qui parle à ce propos d'un «résumé anticipé du Niyogakānḍ̂»), la discussion menée dans ce dernier traité a néanmoins une portée plus large. Maṇdana y discute en effet la thèse, valable tant pour le Veda que pour le langage «mondain», selon laquelle «l'opération d'un énoncé quel qu'il soit trouve son aboutissement dans [la connaissance d'] une obligation » (kartavyatāparyavasāyinin [...] sarvavākyapravrttih - SD 540.4-5 [ $\approx$ M 269.5; G 194.4-5]), alors que la Brahmasiddhi se concentre sur la problématique exégétique. C'est pourtant bien déjà la question des vedāntavākya qui occupe l'essentiel de l'attention de Maṇạana dans le Vidhiviveka, comme le montre sa réfutation, qui fait appel à des raisonnements ne valant que pour les énoncés védiques : portée de l'«injonction de récitation personnelle» (svādhyāyavidhi), caractère impersonnel (apaurușeya) des énoncés du Veda, etc. 79. ViV 29 (svavrtti) M 269.6; G 192.5 (lire vedāntāh hors composé); S S $^{\text {5 }} 40.6$.

80. La question de l'identité du pūrvapakșin réfuté dans cette section du Vidhiviveka est complexe, et ne saurait être entièrement résolue sans une analyse détaillée du passage, qui ne peut être menée à bien ici. Plusieurs éléments suggèrent que Maṇụana a à l'esprit la thèse de Prabhākara identifiant l'objet du Veda à l'obligation (kârrya) sacrificielle: outre un usage répété des concepts d'«obligation» (kartavyatā) et de «commandement» (niyoga) et une citation/paraphrase de la Brhatī 1.1.2 (voir supra, note 65), la locution conclusive alam (...) gurubhir vivädena («Assez de cette dispute avec le/les Guru(s) !»-M 281.4; G 200.5; S $559.2-3$ ) pourrait faire référence au sobriquet bien connu de Prabhākara, surnommé «le Maître» (guru) tant par ses adversaires que par ses partisans. Le commentaire de Vācaspati ne confirme cependant pas directement cette identification, et ne semble en fait pas considérer la discussion principalement comme une polémique à l'encontre des idées de Prabhākara, qui ne sont abordées que dans un second temps (voir Nyāyakanikāa M 273.20; G 195.12; $\mathrm{S}^{\mathrm{D}} 547.17 \mathrm{sq}$.). La section initiale de son commentaire laisse au contraire penser que l'adversaire 
argument de nature philosophique tout autant qu'exégétique. Il semble en effet contradictoire de poser que les énoncés vedāntiques prescrivent une connaissance du soi et sont en même temps la source de cette connaissance. En effet, à moins de supposer deux fonctions distinctes pour le même énoncé - ce que tout Mīmāṃsaka refuse en vertu de la définition de l'unité de l'énoncé par l'unité de son objet (artha $)^{81}$-, cela reviendrait à dire que l'injonction, tout en prescrivant la connaissance du soi, en fournirait aussi le contenu; en d'autres termes, que la seule compréhension de l'ordre suffirait à le voir aussitôt accompli! Comme l'explique bien Mandana: «Si cette connaissance [= la connaissance de la réalité du soi] devait advenir par la parole, il serait inutile d'agir à nouveau pour l'obtenir, tout comme [on n'agit pas pour obtenir] la connaissance de la relation entre un certain acte et un résultat [escompté] ${ }^{82}$ ! (...) De plus, une injonction vise l'action, son intention (vivakșitatva) n'est donc pas [d'exprimer] l'être essentiel d'une chose (vastusvarüpasattā); ainsi, ce qui est saisi par l'injonction [dans votre hypothèse] est [simplement] l'accomplissement [d'un certain acte] en vue de connaître [le soi], et aucune connaissance de la réalité du soi ne peut [donc]

est, de son point de vue, plutôt Kumārila, quoique ce dernier ne soit jamais ni nommé ni cité dans cette portion de la Nyāyakaṇikāa. Ainsi, lorsqu'il traite du «but de l'homme» (purușārtha) dont la présence d'une injonction fonderait le lien avec la connaissance du soi, Vācaspati définit ce dernier précisément dans les termes du Tantravārttika, à savoir comme le «non retour» (apunarāvriotti) de l'adepte dans le saṃsāra après la mort (M 271.17/19; G 193.26/28; S 545.15/18). Vācaspati cite alors à l'appui le même passage de la Chāndogyopanișad (8.15.1: na ca punar āvartate) qu'invoquait déjà Kumārila (Tantravārttika 1.3.29 - vol. 2, p. 227.21-22). L'autre exemple d'énoncé (pseudo-?)upanișadique discuté dans la Nyāyakaṇikā, ātmā jñātavyah ( Le soi est digne d'être connu»), est par ailleurs identique à celui qu'utilise Kumārila dans le Ślokavārttika (voir supra, note 72), et est interprété d'une manière que n'aurait sans doute pas reniée le grand Mīmāṃsaka: àtmā jñātavya iti hi pratipattir àtmani vidhīyate, tatparatvam ca vedāntānām; «En effet, par [1'énoncé] àtmā jñātavyah̆, la connaissance du soi est enjointe, et telle est la visée des [énoncés du] Vedānta» ( $S^{\mathrm{D}}$ 544.10-11 [= M 270.9-10; G 192.26-27]). Enfin, l'usage par Vācaspati d'une analyse de l'injonction en termes d'«effectuation» (bhāvanā-M 271.11-15; G 193.21-24; $\mathrm{S}^{\mathrm{D}}$ 545.14-16) pointe elle aussi davantage en direction du Tantravārttika que de la Brothatī. L'exposé de Maṇdana est lui-même très proche parfois du Tantravārttika d'un point de vue terminologique ou conceptuel. Qu'on compare, par exemple, la définition par Kumārila de l'objet des Upanișad comme une «injonction de connaître la réalité du soi» (ätmatattvajñānavidhāna - voir supra) avec la formulation du pürvapakșin du Vidhiviveka, pour qui les énoncés du Vedānta (vedānta) portent sur une «obligation de connaître la réalité du soi» (ätmatattvapratipattikartavyatā - M 270.1-2, G 192.7 [ $\left.\approx \mathrm{S}^{\mathrm{D}} 540.9\right]$ ). De même, la définition de l'objet de l'injonction comme la «relation entre un acte et un résultat [escompté]» (karmaphalasambandha-M 270.5; G 193.1-2; S $541.1-2$ ), que Mañuana mobilise au début de sa réfutation, est bien celle de Kumārila, non celle de Prabhākara. Le choix d'attaquer Kumārila plutôt que Prabhākara se justifierait d'ailleurs parfaitement de son point de vue puisque, comme on l'a vu, la problématique des upanișad est très probablement encore étrangère à l'auteur de la Brhatī. Il n'est donc pas impossible que Maṇḍana, pour des raisons qui peuvent être aussi bien d'ordre théorique que stratégique, ait choisi d'enrichir une critique originellement dirigée contre Kumārila d'éléments empruntés à la doctrine de Prabhākara, lui donnant ainsi une radicalité qui lui aurait manqué s'il s'était limité aux seules formulations des Vārttika.

81. Voir MīSū 2.1.46: arthaikatvād ekam vākyam (...); «Un énoncé est unique si son objet est unique $(\ldots) »$.

82. Pour l'interprétation de l'exemple karmaphalasambandhabodhavat, voir BS 2.1 (svavrtti): yac chabdād eva jñānam, tad avidheyam, vidhim antareṇa bhāvāt, karmāvabodhavat; «La connaissance [acquise] par la parole ne peut être enjointe, car elle advient même en l'absence d'aucune injonction, à l'instar de la connaissance de l'acte [sacrificiel]» (p. 74.17-18). Comme on l'a vu, la relation entre un acte et un résultat escompté (karmaphalasambandha) constitue, selon Kumārila, l'objet spécifique d'une injonction sacrificielle comme svargakāmo yajeta ( «Que celui qui désire le Ciel sacrifie! »). 
avoir lieu! $»^{83}$. C'est donc bien la connaissance de l'ätman qui constitue l'apport propre des énoncés upanișadiques, et non la seule obligation de le connaître, tout comme l'intention de celui qui prononce un énoncé profane comme iha nidhyādi (« Il y a ici un trésor, etc. ») - pour reprendre l'exemple de Maṇạana ${ }^{84}$ - est bien de manifester l'emplacement d'un trésor, et non pas seulement la nécessité de connaître un tel emplacement.

Cette nouvelle conception de l'indépendance des énoncés vedāntiques ne pouvait cependant aller sans une remise en cause de certains postulats de base de la Mīmāṃsā. Les exégètes anciens avaient en effet fondé leur conception du Veda comme moyen de connaissance à part entière - autrement dit, l'indépendance (nirapekșatva) du Veda par rapport à la perception, l'inférence, etc. - sur une séparation radicale de son domaine de validité par rapport à celui des autres moyens de connaissance valide: la perception et ses dépendances accèdent à ce qui est (bhüta), le Veda à ce qui doit être $(b h \bar{a} v y a)^{85}$. Cette division, qui pouvait encore revêtir pour un Mīmāṃsaka du début du VII ${ }^{\mathrm{e}}$ siècle un caractère d'évidence, s'affaiblit considérablement avec Maṇdana, qui s'efforce au contraire de montrer, selon la formule éclairante de Vācaspati, qu'«il n'existe aucun lien nécessaire entre le fait de [porter] sur un objet existant (bhütārthatva) et le fait de dépendre [d'un autre moyen de connaissance valide] (sāpekșatva) $\gg^{86}$. Ce point fait l'objet d'une brève explication dans le Vidhiviveka, qui forme la matrice d'un long développement dans la Brahmasiddhi (k. 2.10-28 et svavrtti): «[Objection:] mais enfin, on ne saurait parvenir à [établir] la qualité de moyen de connaissance valide (prāmānya) d'un [énoncé] dépourvu de [valeur] injonctive (vidhirahita), consistant [par conséquent] en une [simple] redite (anuvāda) [et] en attente [d'autre chose] (sākānksṣa)! - Qu'est ce donc qui fait de [cet énoncé] une "redite"? S'agit-il (a) du fait [qu'il porte] sur un objet connu par un autre moyen de connaissance valide (pramānāntarādhigatārthatā) ou (b) du fait [qu'il porte] sur un objet existant (bhütārthatā)? (a) Si c'est le fait [qu'il porte] sur un objet connu par un autre moyen de connaissance valide, dans ce cas même un [énoncé védique] dépourvu de [valeur] injonctive (vidhiśūnya) n'est pas une redite, et n'est pas

83. ViV 29 (svavrtti) $:$ [naitat sāram, śabdāt pratipatter utpatteh $<\mathrm{G} \mathrm{S}^{\mathrm{D}}$ : anutpatteh $\mathrm{M}>$ punas tatrāvyāpārāt $<\mathrm{M} \mathrm{G}$ : avyāpāratvāt $\mathrm{S}^{\mathrm{D}>}$, karmaphalasambandhabodhavat. (...) kriyāparatvāe ca vidher vastusvarūpasattāyā avivakșitatvāt tatpratipattyartham anușthānam gamyeta, nātmatattvāvabodhah syāt (M 270.4-272.2; G 193.1-194.2; S $541.1-10$ ). Voir aussi BS 2.4 et svavrtti, p. 76.1218. Traduction: Biardeau 1969: 244.

84. ViV 29 (svavrtti) M 270.2; G 192.8; S 540.11.

85. Notons que cette opposition, durcie par les Mīmāṃsaka plus tardifs (en particulier par Prabhākara), est formulée en des termes encore très vagues par Śabara. Voir Śābarabhāșya ad MīSū 1.1.2 : codanā hi bhütam bhavantam bhavișyantam sūkșmam vyavahitam viprakrșțtam ity evamjātīyakam artham śaknoty avagamayitum, nānyat kim canendriyam; «Car l'injonction [védique] (codanā) peut faire connaître des objets de toutes sortes: [un objet] passé, présent, futur, subtil, dissimulé, lointain... Aucun autre sens (indriya) ne peut en faire autant!» (F 16.12-14). C'est ce qui permet à Maṇuana de présenter, dans le Vidhiveveka comme dans la Brahmasiddhi, ses positions vedāntiques non pas comme en rupture par rapport à la tradition mīmāmssaka, mais comme parfaitement conformes à l'intention de l'auteur du Bhāṣya: ce dernier n'affirme-t-il pas que le Veda fait connaître un objet bhüta («passé», mais aussi «existant»)? Voir sur ce point les deux passages cités supra, note 65.

86. Nyāyakanikā ad ViV 29 (svavrtti): bhūtārthatvasāpekșatvayor na pratibandho sti kaś cit ( $\mathrm{S}^{\mathrm{D}}$ 547.8 [= M 273.11-12; G 194.29]). 
davantage dépendant [d'un autre moyen de connaissance valide] (sāpekșa) [car], étant impersonnel (apaurușeya), il n'est pas de cette sorte ${ }^{87}$. (b) Si c'est le fait [que l'énoncé porte] sur un objet existant, à quoi tient sa dépendance [d'un autre moyen de connaissance valide]? Si [vous affirmez] qu'on observe bien la dépendance [d'un autre moyen de connaissance valide] des énoncés profanes (laukikavacas) [portant] sur un objet existant du fait qu'ils portent sur [un objet] saisi par un autre moyen de connaissance valide ${ }^{88}$, [je réponds que] même les injonctions profanes [prescrivant] la prise d'un médicament, par exemple, sont comme cela ${ }^{89}$. Ainsi [selon votre raisonnement] même un [énoncé] védique porteur d'une [valeur] injonctive serait dépendant [d'un autre moyen de connaissance valide]! Si toutefois [vous affirmez] qu' [un tel énoncé] ne dépend pas [d'un autre moyen de connaissance valide] en raison de son caractère impersonnel, pour la même raison le caractère impersonnel [et donc indépendant] de l'autre [catégorie d'énoncé] est imparable! [On propose:] dans la mesure où un autre moyen de connaissance valide [portant sur son objet] est concevable (sambhava), [un énoncé portant] sur un objet existant est dépendant [d'un autre moyen de connaissance valide], mais pas [un énoncé] porteur d'une [valeur] injonctive, car aucun [autre moyen de connaissance valide] n'est compatible avec l'objet d'une injonction. - Dans ce cas, [l'injonction] profane sera elle aussi indépendante d'un [autre moyen de connaissance valide], ce que nul n'admet $»^{90}$. Pour Maṇdana, le caractère dépendant ou indépendant d'un énoncé - en d'autre termes, sa subordination à la perception, etc. - ne tient donc plus à la nature de son contenu (un objet existant ou à accomplir), mais uniquement à sa provenance. C'est en effet par leur caractère personnel ou impersonnel (paurușeya/apauruseya) - et par lui seul - que se distinguent pour Maṇḍana les énoncés profanes ou védiques, et non plus par la modalité (temporelle, etc.) de leur objet ${ }^{91}$.

87. C'est-à-dire: il ne porte pas sur l'objet d'un autre pramāna, la perception par exemple. Voir

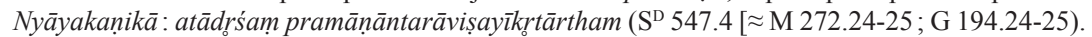
Pour le sens général de l'argument, voir également la Nyāyakaṇikā : jñānapūrvako hi paścād vādo 'nuvādah. apaurușeye tu jūātuh kartur abhāvān na jñānapūrvaka iti nānuvādah; «En effet, une redite (anuvāda), c'est un discours subséquent (paścād vādah), [c'est-à-dire] précédé par une connaissance. Mais dans le cas d'un [énoncé] impersonnel, comme il n'y a pas de sujet connaissant [qui serait] son auteur, [1'énoncé] ne peut être précédé par une connaissance; [un tel énoncé] n'est donc pas une redite» ( $\mathrm{S}^{\mathrm{D}}$ 547.4-5 [= M 272.25-273.8; G 194.25-26]).

88. Si bien qu'on pourrait étendre ce constat aux énoncés assertifs du Veda. Voir Nyāyakaṇikā: ...iti vaidikāny api bhūtārthāni sāpekșāṇi; «..., si bien que même les [énoncés] védiques [portant] sur un objet existant seraient dépendants [d'un autre moyen de connaissance valide]» ( $\mathrm{S}^{\mathrm{D}} 547.10$ [= M 273.14; G 194.31]).

89. C'est-à-dire: dépendantes d'un autre moyen de connaissance valide. Voir Nyāyakaṇikā : tathā sāpekșāh (S $\mathrm{S}^{\mathrm{D}} 547.11$ [= M 273.15; G 194.32]).

90. ViV 29 (svavrtti): nanu vidhirahitasyānuvādarūpasya sākāìkșasya prāmānyam alabhyam. - atha keyam anuvādatā? pramānāntarādhigatārthatā, āho svid bhūtārthatā? pramānāntarādhigatārthatā cet, vidhiśūnyam apy atādrrśam apaurușeyam nānuvādah, sāpekșam vāa. bhütārthatā cet, kiṃkrtā sāpekșatā? yadi laukikavacasām pramānāntarādhigatagocaratvād bhūtārthānām sāpekșatvam drsștam, aușadhapānādișu vidhayo 'pi laukikās tatheti vidhimad vaidikam apy apekșeta. athāpaurușeyatvān nāpekșate, tato 'paurușeyatvam itaratrāpy avāryam iti. atha pramānāntarasambhavād bhütārthasya sāpekșatā, na vidhimatah, vidhyarthe tadasambhavāt. - laukikasyāpi tadanapekșatāprasañgah ( $\mathrm{S}^{\mathrm{D}}$ 542.2-12 [ $\approx \mathrm{M} 272.4-273.7 ;$ G 194.4-195.3]).

91. Voir ViV 29 (svavrtti) : paurușeyatā (...) sāpekșatve hetuh (...), na pramānāntarasambhavah ; «C'est le caractère personnel [d'un énoncé] qui est la cause de sa dépendance [d'un autre moyen 
On voit comment ce qui peut apparaitre de prime abord comme un simple ajustement de la théorie kumārilienne de l'upaniṣad constitue en réalité une fracture majeure dans l'édifice conceptuel de la Mīmāṃsā. Loin d'être un simple ajout à une théorie du Veda qui pourrait demeurer par ailleurs inchangée, l'apparition de la catégorie exégétique des vedānta(vākya) en sape les principaux fondements : la centralité fonctionnelle de l'injonction, l'équation entre la validité du Veda dans le domaine suprasensible et l'appréhension d'un objet non présent, etc. Certes, rien n'indique que Maṇdana Miśra, en mettant ainsi en cause certains présupposés majeurs de l'exégèse telle qu'elle avait été pensée par ses prédecesseurs, eut jamais l'intention de s'opposer à la tradition mīmāmsaka prise dans son ensemble comme le feront les Vedāntin plus tardifs. Ce n'est donc que retrospectivement qu'on fera de lui un «Vedāntin » plutôt qu'un continuateur fidèle - quoique passablement iconoclaste - de l'entreprise herméneutique initiée par Śabara et surtout Kumārila. C'est cependant sur la base de cette Mīmāṃsā «réformée» qu'allait se développer, avec Śankkara et ses successeurs, la tradition scolastique à laquelle on allait plus tard donner le nom d'Uttara-Mīmāṃsā, tradition désormais dotée d'un objet propre et se développant de manière parallèle à la lignée des commentateurs sur les Mìmāmsāsūtra.

\section{Conclusion}

À l'issue de cette enquête, la naissance du Vedānta comme école d'exégèse indépendante ne semble pas résulter de l'adoption superficielle, pour des raisons de prestige, des méthodes et présupposés de la Mīmāṃsā par un courant philosophique originellement autonome, mais apparaît plutôt comme le produit d'une évolution interne à l'exégèse entre le $\mathrm{V}^{\mathrm{e}}$ et le viII ${ }^{\mathrm{e}}$ siècle. On constate en effet durant cette période un effort constant et multiforme de la part des penseurs brahmaniques pour intégrer au Veda tel qu'ils le conçoivent une catégorie de textes, les Upanișad, possédant déjà un caractère d'autorité mais dépourvus de statut exégétique précis. Cette évolution s'accompagne d'une double modification dans la manière dont les Vedāntin envisagent leur propre tradition scripturaire. Canonisation du corpus vedāntique, tout d'abord: ce qui n'était encore pour Bhartrhari qu'un ensemble d'opinions mutuellement contradictoires, d'inspiration védique certes mais situées en marge d'un texte essentiellement voué à l'enseignement du dharma, devient dans les siècles qui suivent partie intégrante - sinon le cœur même - du Texte Sacré. La doctrine que ces textes dispensent, de simple produit des pérégrinations de l'esprit humain, devient par ailleurs la pensée du Veda lui-même, dont il est alors légitime de rechercher la cohérence (samanvaya) par-delà la diversité des textes. Objectification du texte védique, ensuite: les premiers Vedāntin voyaient encore dans les textes upanișadiques des précurseurs au sein d'une tradition ininterrompue, qu'il était donc loisible d'imiter, de paraphraser ou de prolonger par une élaboration théorique

de connaissance valide] (...), et non pas le fait qu'un autre moyen de connaissance valide [portant sur le même objet] soit concevable» ( $S^{\mathrm{D}} 543.23$ [= M 274.5-6, G 194.7-8]). 
autonome. Cette attitude se rencontre beaucoup plus rarement chez les Vedāntin postérieurs au vII siècle Pour la plupart d'entre eux, le Veda n'est plus cette source d'inspiration qu'on peut à loisir méditer et enrichir par ses propres réflexions. Étant à présent partie intégrante du Veda éternel, le texte des Upanișad est devenu objet d'étude, un objet dont l'extériorité laisse place à l'analyse, à la mise en système et au commentaire suivi, mais établit en même temps avec son interprète une distance d'ordre ontologique (plus que simplement chronologique), et désormais irréductible. 


\section{Abréviations}

ĀŚ $\quad$ Ágamaśāstra, de Gauḍapāda.

BĀU Brhadāranyakopaniṣad.

BS Brahmasiddhi, de Maṇạana Miśra.

BS̄̄ Brahmasūtra.

BSūBh Brahmasūtrabhāṣya, de Śañkara.

ChU Chāndogyopanișad.

MHK Madhyamakahrdayakārikā, de Bhavya/Bhā(va)viveka.

MīSū Mìmāmșāsūtra.

MuU Munḍakopanișad.

$\operatorname{PrPr}_{1} \quad$ Prakīrnaprakāśa, de Helārāja (vol. 1).

ŚvU Śvetāśvataropaniṣad.

TaiU Taittirìyopanișad.

ViV Vidhiviveka, de Mandana Miśra.

VP(SV) Vākyapadīya(svavrtti), de Bhartrohari.

YD Yuktidīpikā.

\section{Bibliographie}

\section{Textes sanskrits}

Āgamaśāstra (Gauḍapāda), voir Bouy 2000.

Bhagavadgītā, éd. Wāsudev Laxmaṇ Shāstrī Paṇśīkar, Bombay, Nirṇaya Sāgar Press, 1936 ( $2^{\mathrm{e}}$ éd.).

Bhāmatī (Vācaspati Miśra), voir Brahmasūtrabhāṣya.

Brahmasiddhi (Maṇạana Miśra), éd. S. Kuppuswami Sastri, Madras, Government Press (Madras Government Oriental Series 4), 1937 (réimpression Bénarès, Chowkhamba Sanskrit Series Office, 2010).

Brahmasūtrabhāṣya (Śañkara), éd. N. S. Anantakrishna Shastri \& Vasudev Laxman Shastri Pansikar, Bénarès (Varanasi), Krishnadas Academy (Krishnadas Sanskrit Series 25), 2000.

Brohatī (Prabhākara):

C: éd. A. Chinnaswami Sastri, Bénarès, Vidya Vilas Press (Chowkhamba Sanskrit Series 391), 1929.

M : éd. S. K. Ramanatha Sastri, Madras, The University of Madras (Madras University Sanskrit Series 3.1), 1934.

Gìtābhāṣya (Śankkara), voir Bhagavadgītā.

Madhyamakahrdayakārikā (Bhavya/Bhā[va]viveka), voir QvARNSTRÖM 1989.

Mahābhāṣya (Patañjali), éd. F. Kielhorn, revue par K. V. Abhyankar (vol. 1), Poona, Bhandarkar Oriental Research Institute, 1985 ( $4^{\mathrm{e}}$ éd. $-1^{\text {re }}$ éd. Poona, 1880).

Mīmāṃsāsūtra, voir Śābarabhāṣya. 
Nayaviveka (Bhavanātha), éd. S. K. Rāmanātha Śāstrī, Madras, University of Madras (Madras University Sanskrit Series 12), 1937.

Nyāyakaṇikā (Vācaspati Miśra), voir Vidhiviveka.

Paramārthasāra (Ādiśeșa), éd. T. Gaṇapati Śāstrī, Trivandrum, Government of His Highness the Maharajah of Travancore (Trivandrum Sanskrit Series 12), 1911.

Prakīrnaprakāśa (Helārāja), voir Vākyapadīya Kāṇ̣̣ 3.1.

Rjuvimalā (Śālikanātha), voir Brhatī.

Śābarabhāṣya :

F : FraUWALLner 1968.

1.2.1-2.1.49: éd. Gaṇeśaśāstrī Jośī (vol. 2), Pune (Punyapattana), Ānandāśrama (Ānandāśramasaṃskṛtagranthāvaliḥ 97.2), 1981 (3éd.).

4.1.1-7.4.20 : éd. par les paṇụits de l’Ānandāśrama (vol. 5), Pune (Punyapattana), Ānandāśrama (Ānandāśramasaṃskṛtagranthāvalị 97.5), 1984 ( $2^{\mathrm{e} e ́ d}$.).

Ślokavārttika (Kumārila), éd. Swāmī Dvārikādāsa Śāstrī. Bénarès (Varanasi), Ratna Publications (Ratnabharati Series 4), 1978.

Sphutākșarā (= Paddhati) (Śrīvrșabha/Vrșạabhadeva), voir Vākyapadīya Kānda 1.

Tantravārttika (Kumārila), voir Śābarabhāṣya et HARIKAI 2007, 2009 et 2011.

Tarkajvālā (attribuée à Bhavya/Bhā[va]viveka), voir QVARNSTRÖM 1989.

Vākyapadīya (Bhartrhari), voir RAU $1977^{92}$.

Vākyapadīya Kāṇda 1, éd. K. A. Subramania Iyer, Poona, Deccan College (Deccan College Monograph Series 32), 1966.

Vākyapadīya Kānḍ $2^{93}$ :

Éd ${ }^{1939-1940}$ : éd. Cārudeva Śāstrī, Lahore (Lāhor), Śrī Rāma Lāla Kapūr Nyāsasamiti, 1939-1940 (= vi $\left.{ }^{\circ} 1996\right)$.

Éd $^{1980}$ : éd. Raghunātha Śarmā (?), Bénarès (Varanasi), Sampurnanand Sanskrit Vishvavidyalaya (Sarasvatībhavana-Granthamālā 91), 1980

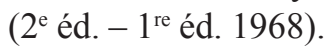

Éd $^{1983}$ : éd. K. A. Subramania Iyer, Delhi-Varanasi-Patna, Motilal Banarsidass, 1983.

Vākyapadīya Kāṇ̣a 3.1, éd. K.A. Subramania Iyer, Pune, Deccan College (Deccan College Monograph Series 21), 1994.

Vedavādadvātrimssikā (Siddhasena Divākara), voir QvARNSTRÖM 2003.

92. Sauf indication contraire, le texte des $k \bar{a} r i k \bar{a}(\mathrm{VP})$ est cité d'après cette édition.

93. Sauf indication contraire, le texte de la vrtti du second kāṇda (VPSV 2) est cité d'après l'édition de K.A. Subramania Iyer (Éd $\left.{ }^{1983}\right)$. 
Vidhiviveka (Maṇụana Miśra):

$\mathrm{S}^{\mathrm{D}}$ : édition critique inédite du Vidhiviveka, de la Nyāyakanikā de Vācaspati Miśra et de ses deux commentaires inédits par Elliot M. Stern; version provisoire communiquée par l'éditeur le 5 août 2015.

M: éd. Rāma Śāstrī Tailangga Mānavallī, Bénarès (Kāśīi), «Medical Hall» Mudraṇālaya (Réimpression du texte paru à Bénarès dans la revue «The Pandit»), 1907.

G: éd. Mahaprabhu Lal Goswami, Bénarès (Varanasi), Tara Publications (Prācyabhāratī Series 8), 1978.

Yuktidīpikā, voir WeZler \& Motegi 1998.

\section{Études et traductions}

AKLuJKar, Ashok

1991 «Bhartrhari's concept of the Veda», in J. BronkHorst \& M. Deshrande (éd.), Panels of the VIIth World Sanskrit Conference, Volumes IV and V, Leiden, E.J. Brill, p. 1-18.

2009 «Veda Revelation according to Bhartrhari», in M. CHATURVEDI (éd.), Bhartrhari: Language, Thought and Reality (Proceedings of the International Seminar - Delhi, December 12-14, 2003), Delhi, Motilal Banarsidass, p. 1-97.

2011 «Unity of the Mīmāṃsas. How Historiography Hides History», in R. V. Tripathi et al. (éd.), Vācaspativaibhavam. A Volume in Felicitation of Professor Vachaspati Upadhyaya, New Delhi, D. K. Printworld, p. 821-900.

Biardeau, Madeleine

1964 Bhartrohari. Vākyapadīya Brahmakāṇḍa, avec la Vrotti de Harivrssabha (traduction, introduction et notes), Paris, Collège de France/de Boccard (Publications de l'Institut de Civilisation Indienne 24).

1969 La Philosophie de Maṇdana Miśra vue à partir de la Brahmasiddhi, Paris, École française d'Extrême-Orient (PEFEO 76).

Bouy, Christian

2000 L'Āgamaśāstra: un traité vedāntique en quatre chapitres. Texte, traduction et notes. Paris, Collège de France/de Boccard (Publications de l'Institut de Civilisation Indienne 69).

BRONKHORST, Johannes

2007 «Vedānta as Mīmāmsā», in J. BRONKHORST (éd.), Mìmāmsāa and Vedānta. Interaction and Continuity, Delhi, Motilal Banarsidass (Papers of the 12th World Sanskrit Conference vol. 10.3), p. 1-91.

2014 «Mīmāṃsāsūtra and Brahmasūtra», Journal of Indian Philosophy 42.4, p. 463-469. 
DAVID, Hugo

2013 «Action Theory and Scriptural Exegesis in Early AdvaitaVedānta (1): Maṇụana Miśra on upadeśa and iștasāadhanatā », in V. Eltschinger \& H. Krasser (éd.), Scriptural Authority, Reason and Action. Proceedings of a Panel at the 14th World Sanskrit Conference, Kyoto, September 1st-5th 2009, Vienne, Österreichische Akademie der Wissenschaften (Beiträge zur Kultur- und Geistesgeschichte Asiens 79), p. 269-316.

FERRANTE, Marco

2013 «Vrș̣abhadeva's Sphuțākṣarā on Bhartronari’s Metaphysics: Commentarial Strategy and New Interpretations », Journal of Indian Philosophy 41.2, p. 133-149.

FraUWALLNER, Erich

1953 Geschichte der indischen Philosophie. I. Band, Salzburg, Otto Müller Verlag.

1968 Materialen zur ältesten Erkenntnislehre der Karmamīmāmsāa, Vienne, Österreichische Akademie der Wissenschaften (Veröffentlichung der Kommission für Sprachen und Kulturen Süd- und Ostasiens 6).

GARGE, Damodar Vishnu

1952 Citations in Śabara Bhāṣya (a Study), Poona, Deccan College Post-graduate and Research Institute (Deccan College Dissertation Series 8).

GERSCHHEIMER, Gerdi

2007 «Les "six doctrines de speculation" (satțarkī). Sur la catégorisation variable des systèmes philosophiques dans l'Inde classique», in K. Preisendanz (éd.), Expanding and Merging Horizons: Contributions to South Asian and Cross-Cultural Studies in Commemoration of Wilhelm Halbfass, Vienne, Österreichische Akademie der Wissenschaften (Philosophisch-Historische Klasse, Denkschriften 351; Beiträge zur Kultur- und Geistesgeschichte Asiens 53), p. 239-258.

GondA, Jan

1977 The Ritual Sūtras, Wiesbaden, Otto Harrassowitz (A History of Indian Literature 1.2).

HaLBFASS, Wilhelm

1988 India and Europe: an Essay in Understanding, Albany, State University of New York Press.

1991 Tradition and Reflection. Explorations in Indian Thought, Albany, State University of New York Press.

HARIKAI Kunio

2007 «Sanskrit text of the Tantravārttika. Adhyāya 1, Pāda 2 (Chapters of arthavāda and mantra). Collated with four Manuscripts», Annual Report of Medical Anthropology and Humanity (Saga Medical School) 2, p. 1-69. 
2009 «Sanskrit text of the Tantravārttika. Adhyāya 1, Pāda 3, Adhikarana 4-6. Collated with six manuscripts », South Asian Classical Studies 4, p. 359-396.

2011 «Sanskrit text of the Tantravārttika, Adhyāya 1, Pāda 3, Adhikaraṇa 9. Vyākaraṇa Adhikaraṇa. Collated with five manuscripts », South Asian Classical Studies 6, p. 267-304.

Houben, Jan E. M.

1995 The Sambandha-Samuddeśa (Chapter on Relation) and Bhartrhari's Philosophy of Language, Groningen, Egbert Forsten (Gonda Indological Studies 2).

IYER, K.A. Subramania

1969 Bhartrhari. A Study of the Vākyapadīya in the Light of the Ancient Commentaries, Pune, Deccan College (Building Centenary and Silver Jubilee Series 68).

1977 The Vākyapadīya of Bhartrhari, kānḍa 2 (English Translation With Exegetical Notes), Delhi-Varanasi-Patna, Motilal Banarsidass.

JACOB, Colonel G.A.

1988 Upanișadvākyakośaḥ. A Concordance to the Principal Upanishads and Bhagavadgita, Delhi, Pallav Prakashan, 3 vol. (réimpression - $1^{\mathrm{e}}$ éd. Bombay, 1891).

JACOBI, Hermann

1911 "The Date of the Philosophical Sūtras of the Brahmans », Journal of the American Oriental Society 31, p. 1-29.

1970 Kleine Schriften, B. KÖLVER (éd.), Wiesbaden, Franz Steiner.

JHĀ, Ganganatha

1964 Pūrva-Mìmāmṣā in its Sources, Bénarès (Varanasi), Banaras Hindu University ( $2^{\mathrm{e}}$ éd. $-1^{\mathrm{e}}$ éd. 1942).

KeITH, Arthur Berriedale

1920 A History of Sanskrit Literature, Oxford, Oxford University Press.

Krasser, Helmut

2012 «Bhāviveka, Dharmakīrti and Kumārila», in F. Voegeli, V. Eltschinger, D. Feller, M.P. Candotti, B. Diaconescu \& M. Kulkarni (éd.), Devadattīyam. Johannes Bronkhorst Felicitation Volume, Bern, Peter Lang (Worlds of South and Inner Asia 5), p. 535-594.

LAMOTTE, Étienne

1987 L'Enseignement de Vimalakīrti (Vimalakīrtinirdeśa), traduit et annoté, Louvain, Université Catholique de Louvain (Publications de l'Institut Orientaliste 35).

Mesquita, Roque

1994 «Die Idee der Erlösung bei Kumārilabhaț̣a», Wiener Zeitschrift für die Kunde Süd- und Ostasiens 38, p. 451-484. 
NAKAmURA Hajime

1983 A History of Early Vedānta Philosophy. Part One (Traduction anglaise de Shoki No Vedanta Tetsugaku, vol. 1-2), T. LEGGETt, S. Mayeda, T. Unno et al. (trad.), Delhi, Motilal Banarsidass.

2004 A History of Early Vedānta Philosophy. Part Two (Traduction anglaise de Shoki No Vedanta Tetsugaku, vol. 3-4), H. NAKAMURA, T. LEGGETT et al. (trad.), S. MAYEDA (éd.), Delhi, Motilal Banarsidass.

Parpola, Asko

1981 et 1994 «On the formation of the Mìmāms à and the problems concerning Jaimini. With particular reference to the teacher quotations and the Vedic schools », Wiener Zeitschrift für die Kunde Südasiens und Archiv für indische Philosophie 25, p. 145-177 ( $1^{\text {re }}$ partie $)$ et 38 , p. 293-308 ( $2^{\mathrm{e}}$ partie).

QVARNSTRÖM, Olle

1989 Hindu Philosophy in Buddhist Perspective. The Vedāntatattvaviniścaya Chapter of Bhavya 's Madhyamakahrdayakārikā, Lund, Plus Ultra (Lund Studies in African and Asian Religions 4).

2003 «Early Vedānta Philosophy Preserved by the Jain Tradition: the Vedavādadvātriṃśikā of Siddhasena Divākara », in O. Qvarnström (éd.), Jainism and Early Buddhism: Essays in Honor of Padmanabh S. Jaini, part 1, Fremont (California), Asian Humanities Press, p. 575-593.

RAU, Wilhelm

1977 Bhartrharis Vākyapadīya. Die mūlakārikās nach den Handschriften herausgegeben und mit einem pāda-index versehen, Wiesbaden, Franz Steiner/Deutsche Morgenländische Gesellschaft (Abhandlungen für die Kunde des Morgenlandes 42.4).

Renou, Louis

1947 Les écoles védiques et la formation du Veda, Paris, Imprimerie nationale (Cahiers de la Société Asiatique 9).

RuEGG, David Seyfort

1981 The Literature of the Madhyamaka School of Philosophy in India, Wiesbaden, Otto Harrassowitz (A History of Indian Literature 7.1).

SenART, Émile

1934 Brohad-Āraṇyaka-Upanișad (traduite et annotée), Paris, Les Belles Lettres (Collection Émile Senart 3) (second tirage 1967).

UPADHYE, A. N.

1971 Siddhasena's Nyāyāvatāra and Other Works (with a Bibliographical Review), Bombay, Jaina Sahitya Vikasa Mandala.

VERPOORTEN, Jean-Marie

1987 Mìmāmsā Literature, Wiesbaden, Otto Harrassowitz (A History of Indian Literature 6.5). 
WezLer, Albrecht \& Shujun Motegi

1998 Yuktidīpikā. The Most Significant Commentary on the Saṃkhyākārikā, critically edited (vol. 1), Stuttgart, Franz Steiner Verlag (Alt- und Neu-Indische Studien 44).

\section{Yoshimizu Kiyotaka}

2007 «Kumārila's Reevaluation of the Sacrifice and the Veda from a Vedānta Perspective», in J. BronkHORst (éd.), Mìmāmsāa and Vedānta. Interaction and Continuity, Delhi, Motilal Banarsidass, p. 201-253. 